\title{
Pharmacology of Cardiac Potassium Channels
}

Gui-Rong $\mathrm{Li}^{1,2}$ and Ming-Qing Dong ${ }^{1}$

Departments of Medicine ${ }^{1}$ and Physiology, ${ }^{2}$ Li Ka Shing Faculty of Medicine, the University of Hong Kong, Hong Kong SAR China

Running title: $\mathrm{K}^{+}$channel pharmacology

Key words. $\mathrm{K}^{+}$channels; cardiomyocytes; pharmacology; cardiac arrhythmias; antiarrhythmic drugs

\section{Correspondence to:}

Dr. Gui-Rong Li, L4-59, Laboratory Block, FBM, Li Ka Shing Faculty of Medicine, The University of Hong Kong, 21 Sassoon Road, Pokfulam, Hong Kong SAR China Tel: 852-2819-9513, Fax: 852-2855-9730; email: grli@hkucc.hku.hk 


\begin{abstract}
Cardiac $\mathrm{K}^{+}$channels are cardiomyocyte membrane proteins that regulate $\mathrm{K}^{+}$ion flow across the cell membrane on the electrochemical gradient, and determine the resting membrane potential and the cardiac action potential morphology and duration. Several $\mathrm{K}^{+}$channels have been well studied in the human heart. They include the transient outward $\mathrm{K}^{+}$current $\mathrm{I}_{\mathrm{tol}}$, the ultra-rapidly delayed rectifier current $\mathrm{I}_{\mathrm{Kur}}$, the rapidly and slowly delayed rectifier currents $\mathrm{I}_{\mathrm{Kr}}$ and $\mathrm{I}_{\mathrm{Ks}}$, the inward rectifier $\mathrm{K}^{+}$current $\mathrm{I}_{\mathrm{K} 1}$, and ligand-gated $\mathrm{K}^{+}$channels, including ATP-sensitive $\mathrm{K}^{+}$current ( $\mathrm{I}_{\mathrm{KATP}}$ ) and acetylcholine-activated current $\left(\mathrm{I}_{\mathrm{KACh}}\right)$. Regional differences of $\mathrm{K}^{+}$channel expression contribute to the variable morphologies and durations of cardiac action potentials from sinus node and atrial to ventricular myocytes, and different ventricular layers from endocardium and midmyocardium to epicardium. They also show different responses to endogenous regulators and/or pharmacological agents. $\mathrm{K}^{+}$channels are well-known targets for developing novel antiarrhythmic drugs that can effectively prevent/inhibit cardiac arrhythmias. Especially atrial specific $\mathrm{K}^{+}$channel currents $\left(\mathrm{I}_{\mathrm{Kur}}\right.$ and $\mathrm{I}_{\mathrm{KACh}}$ ) are the targets for developing atrial-selective anti-atrial fibrillation drugs, which has been greatly progressed in recent years. This chapter concentrates on recent advances in intracellular signaling regulation and pharmacology of cardiac $\mathrm{K}^{+}$channels under physiological and pathophysiological conditions.
\end{abstract}

Abbreviations: AF, atrial fibrillation; $\mathrm{I}_{\mathrm{Kur}}$, ultra-rapidly delayed rectifier $\mathrm{K}^{+}$current; $\mathrm{I}_{\text {to } 1}$, transient outward $\mathrm{K}^{+}$current; $\mathrm{I}_{\mathrm{KACh}}$, acetylcholine-activated $\mathrm{K}^{+}$current; $\mathrm{I}_{\mathrm{KATP}}$, ATP-sensitive $\mathrm{K}^{+}$current; $\mathrm{I}_{\mathrm{Kr}}$, rapidly delayed rectifier $\mathrm{K}^{+}$current; $\mathrm{I}_{\mathrm{Ks}}$, slowly delayed rectifier $\mathrm{K}^{+}$current; $\mathrm{hERG}$, human ether-à-go-go-related gene; Kir, inward rectifier $\mathrm{K}^{+}$channels; SUR, sulfonylurea receptor; $\mathrm{K}_{2} \mathrm{p}$, two pore $\mathrm{K}^{+}$channels; ECG, electrocardiogram; EADs, early afterdepolarizations; TdPs, Torsade de Pointes; APD, action potential duration; 4-AP, 4-aminopyrodine; ERP, effective refractory period; LQTs, long QT syndrome; SQTs, short QT syndrome; PKA, protein kinase A; PLC, phospholipase C; PKC, protein kinase C; PTK, protein tyrosine kinase; CaMKII, $\mathrm{Ca}^{2+} /$ calmodulin-dependent protein kinase II; PIP2, phosphatidylinositol 4,5-bisphosphate; EGFR, epidermal growth factor receptor; $\operatorname{sarcK}_{\text {ATP, }}$

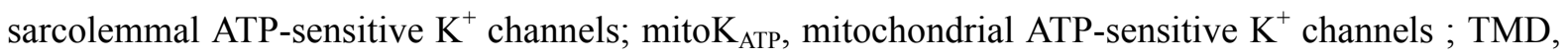
Transmembrane domains 


\section{Introduction}

Cardiac $\mathrm{K}^{+}$channels play a pivotal role in maintaining normal cardiac electrical activity. They regulate the resting membrane potential and excitability, participate in the repolarization and determine the shape and duration of cardiac action potential. Malfunction of $\mathrm{K}^{+}$channels, due to either congenital encoded gene mutations or drug blockade, alters not only the cardiomyocyte excitability, but also the electrical balance of depolarization and repolarization and thus causes a long QT interval or short QT interval of the electrocardiogram and underlies different types of cardiac arrhythmias (Kannankeril and Roden, 2007; Zareba and Cygankiewicz, 2008). Therefore, cardiac $\mathrm{K}^{+}$channels are important targets of antiarrhythmic drugs.

It is well recognized that the shape and duration of cardiac action potential are determined by a balance (i.e. sequential activation and inactivation) of inward currents and outward currents (Nerbonne and Kass, 2005). Figure 1 schematically illustrates the time course of different current contribution to the action potentials of human atrial and ventricular myocytes. The inward currents include voltage-gated $\mathrm{Na}^{+}$current $\left(\mathrm{I}_{\mathrm{Na}}\right)$ responsible for the phase 0 depolarization and L-type $\mathrm{Ca}^{2+}$ current $\left(\mathrm{I}_{\mathrm{Ca} . \mathrm{L}}\right)$ responsible for maintaining plateau (phase 2) of the action potential. The inward component of electrogenic $\mathrm{Na}^{+}-\mathrm{Ca}^{2+}$ exchanger may also contribute to the phase 2 of the action potential.

The outward currents are mainly carried by different $\mathrm{K}^{+}$channels in human cardiac myocytes. They contribute to repolarization of different phases of the action potential. These $\mathrm{K}^{+}$currents include the inward rectified $\mathrm{K}^{+}$current $\mathrm{I}_{\mathrm{K} 1}$, the transient outward $\mathrm{K}^{+}$current $\mathrm{I}_{\mathrm{tol}}$, the ultra-rapidly delayed rectifier $\mathrm{K}^{+}$current $\mathrm{I}_{\mathrm{Kur}}$, rapidly and slowly delayed rectifier $\mathrm{K}^{+}$currents $\left(\mathrm{I}_{\mathrm{Kr}}\right.$ and $\left.\mathrm{I}_{\mathrm{Ks}}\right)$, acetylcholine-regulated $\mathrm{K}^{+}$current $\left(\mathrm{I}_{\mathrm{KACh}}\right)$, and ATP-sensitive $\mathrm{K}^{+}$current ( $\mathrm{I}_{\mathrm{K} . \mathrm{ATP}}$ ).

\section{2. $\mathrm{K}^{+}$channel classification.}

\section{Diversity of $\mathbf{K}^{+}$channels}

$\mathrm{K}^{+}$channels are the most widely distributed type of ion channels composed of $\alpha$-subunits and $\beta$-subunits (Snyders, 1999). The $\alpha$-subunits of $\mathrm{K}^{+}$channels are characterized by 1 ) an ion conducting pore through which $\mathrm{K}^{+}$ions pass through the plasma membrane; 2) a $\mathrm{K}^{+}$selectivity filter in the $\mathrm{P}$ loop from each subunit which have their electro-negative carbonyl oxygen atoms aligned towards the centre of the filter pore and form an anti-prism similar to a water solvating shell around each $\mathrm{K}^{+}$binding site; and 3 ) a gating machinery that controls the switch between open and close states in response to either changes in membrane potential or a ligand (Snyders, 1999). The cytoplasmic N- and C-termini of $\alpha$-subunits are also important functional domains. The pore-forming subunits homogenously form functional channels (MacKinnon, 1995). $\mathrm{K}^{+}$ channels have a tetrameric structure in which four identical $\alpha$-subunits associate to form a fourfold symmetric complex arranged around a central ion conducting pore (MacKinnon, 1995). Alternatively four related but not identical $\alpha$-subunits may associate to form heterotetrameric complexes.

The classification of $\mathrm{K}^{+}$channels is based upon the primary amino acid sequence of the pore-containing $\alpha$-subunits. Three groups (Fig. 2) with six, two, or four putative transmembrane segments are recognized, including 1) voltage-gated $\mathrm{K}^{+}(\mathrm{Kv})$ channels containing six transmembrane regions (S1-S6) with a single pore loop formed by the S5 and S6 segments and S5-S6 linker. The S4 segment is rich in positively charged residues and serves as the voltage sensor (e.g. $\mathrm{I}_{\mathrm{tol}}, \mathrm{I}_{\mathrm{Kur}}, \mathrm{I}_{\mathrm{Kr}}$, and $\mathrm{I}_{\mathrm{Ks}}$ ); 2) inward rectifier $\mathrm{K}^{+}$(Kir) channels containing two transmembrane domains (M1-M2) with intracellular $\mathrm{N}$ - and C-termini, and a single pore loop formed by the $\mathrm{M} 1$ and $\mathrm{M} 2$ domains (e.g. $\mathrm{I}_{\mathrm{K} 1}, \mathrm{I}_{\mathrm{KACh}}$, and $\left.\mathrm{I}_{\mathrm{KATP}}\right)$; and 3) two-pore $\mathrm{K}^{+}\left(\mathrm{K}_{\mathrm{P} 2}\right)$ channels containing four transmembrane domains (M1-M4), intracellular N- and C-terminus, and two pore regions related to background or leak channels (e.g. TWIK, TASK, TREK and THIK) (Gurney and Manoury, 2009; Snyders, 1999).

\section{II. $\beta$-Subunits of $\mathbf{K}^{+}$channels}

Most $\mathrm{K}^{+}$channels heterogeneously assemble with the auxiliary $\beta$-subunits in native cells (Fig. 2). The $\beta$-subunits are either cytoplasmic proteins (e.g. Kv $\beta 1-4, \mathrm{KChIP}$ ) or transmembrane proteins, such as minK and minK-related proteins (MiRPs) encoded by KCNE gene family, and large ATP binding cassette (ABC) transport-related proteins, such as the sulfonylurea receptors (SUR) for the inward rectifiers Kir6.1-6.2 (Snyders, 1999; Stephan et al., 2006). Most $\beta$-subunits assemble with $\alpha$-subunits and act as a molecular chaperone of the $\alpha$-subunits in regulating the channel gating kinetics, pharmacology, folding/coassembly, trafficking or cell surface expression (Bett and Rasmusson, 2008; Martens et al., 1999; Xu et al., 2009). Both $\alpha$-subunits and $\beta$-subunits are pharmacological targets. Cardiac $\mathrm{K}^{+}$channels are also regulated by numerous endogenous molecules and signals. The complex interaction between $\alpha$-subunits, $\beta$-subunits and endogenous modulators represents diversity of native cardiac potassium currents (Snyders, 1999).

\section{Cardiac voltage-gated $\mathrm{K}^{+}(\mathrm{Kv})$ channels I. The transient outward $\mathrm{K}^{+}$current $\mathrm{I}_{\mathrm{to1}}$}


The transient outward current $\mathrm{I}_{\mathrm{to}}$, is composed of two components, i.e. 4-aminopyridine (4-AP) sensitive transient outward $\mathrm{K}^{+}$current $\left(\mathrm{I}_{\mathrm{to} 1}\right)$ and $\mathrm{Ca}^{2+}$-activated transient outward $\mathrm{Cl}^{-}$current $\left(\mathrm{I}_{\mathrm{to} 2}\right)$ in some species $(\mathrm{Li}$ et al., 1995). $\mathrm{I}_{\text {to2 }}$ is not present in human cardiac myocytes, and therefore is not discussed here. $\mathrm{I}_{\mathrm{to1}}$ is a voltage-gated and $\mathrm{Ca}^{2+}$-independent $\mathrm{K}^{+}$current that is rapidly activated and inactivated in response to depolarization, and contributes to the early repolarization (phase 1) of the action potential in human cardiac myocytes (Fig. 1). Density of $\mathrm{I}_{\text {tol }}$ is greater in atria than ventricles, and is 3-4 folds greater in ventricular midmyocardial (M) cells and/or subepicardial cells than in subendocardial cells (Li et al., 1995; Li et al., 1998), therefore $I_{\text {tol }}$ contributes significantly to the phase 1 of the action potentials in these regional myocytes to maintain normal cardiac heterogeneous electrophysiology.

\section{A. Molecular identification of $\mathbf{I}_{\mathbf{t o 1}}$}

Kv4.3 (KCND3) is the dominant candidate coding for cardiac $\mathrm{I}_{\mathrm{to1}}$ in human hearts (Dixon et al., 1996). Kv4.3 channel mRNA and/or protein are significantly expressed in human atrium and ventricle (Gaborit et al., 2007; Kaab et al., 1998) and in canine hearts (Zicha et al., 2004), and display a gradient expression in human and canine ventricular wall from endocardium to epicardium (Zicha et al., 2004), comparable to the region-dependent $\mathrm{I}_{\text {to1 }}$ ( $\mathrm{Li}$ et al., 1998; Liu et al., 1993; Nabauer et al., 1996). Kv4.3 assembles with cytoplasmic KChIPs to form $\mathrm{I}_{\mathrm{to} 1}$ channels (Zicha et al., 2004). In addition, DPP6 (dipeptidyl aminopeptidase-like protein 6) is another putative subunit of cardiac Kv4.3 (Radicke et al., 2005). Moreover, the potential contribution of Kv1.4 channels to human ventricular $\mathrm{I}_{\mathrm{tol}}$ can not be excluded (Po et al., 1992; Snyders, 1999).

The downregulation of cardiac $\mathrm{I}_{\text {tol }}$ frequently occurs in failing hearts associated with a prolonged APD (Li et al., 2002; Li et al., 2004). The reduction of $\mathrm{I}_{\text {tol }}$ likely contributes to the diminished phase 1 amplitude of action potential, and also partially to the prolonged APD and early afterdepolarizations (EADs) in failing hearts ( $\mathrm{Li}$ et al., 2002; Li et al., 2004). In patient with chronic atrial fibrillation (AF) and canine with experimental AF, atrial $\mathrm{I}_{\text {tol }}$ and/or Kv4.3 gene and/or protein are also downregulated (Brundel et al., 2001; Grammer et al., 2000; Yue et al., 1999).

\section{B. Signaling regulation of $\mathbf{I}_{\text {to1 }}$}

The gating properties and kinetics of cardiac $\mathrm{I}_{\text {tol }}$ are modulated by various endogenous molecules and signal pathways including serine/threonine and tyrosine phosphorylation. $\alpha$-Adrenergic stimulation inhibits cardiac $\mathrm{I}_{\text {tol }}$ in rabbit ventricular myocytes (Fedida et al., 1990) and in human cardiac myocytes and cloned hKv4.3 current expressed in mammalian cells (Po et al., 2001), which may be mediated by protein kinase C (PKC), since the PKC activator phorbol 12-myristate 13-acetate (PMA) exhibits a similar inhibition of rat cardiac $\mathrm{I}_{\text {tol }}$ and $\mathrm{Kv} 4.2 / \mathrm{Kv} 4.3$ currents (Nakamura et al., 1997). In addition, c-Src tyrosine kinase increases hKv4.3 current by phosphorylating the channels through the associated macromolecular complex, which is mediated by the SH2 and SH3 domains of c-Src kinases (Gomes et al., 2008).

Activation of $\mathrm{Ca}^{2+} /$ calmodulin-dependent protein kinase II (CaMKII) slows the inactivation and accelerates the recovery from inactivation of Kv4.3 channels via directly phosphorylating S550 located in C-terminus (Sergeant et al., 2005). SAP97, one of the membrane-associated guanylate kinase proteins, participates in CaMKII dependent regulation of cardiac Kv4.3/Kv4.2 channels (El-Haou et al., 2009). Nitric oxide is a diffusible messenger that inhibits $\mathrm{Kv} 4.3$ channels and human $\mathrm{I}_{\text {tol }}$ mediated by activating adenylate cyclase and the subsequent activation of PKA and the serine/threonine phosphatase 2A (Gomez et al., 2008). The increase of the bioavailability of atrial nitric oxide could partially restore the duration of the plateau phase of remodeled action potential by inhibiting $\mathrm{I}_{\text {tol }}$. Angiotensin II regulates the membrane distribution and gating properties of Kv4.3 channels (Doronin et al., 2004).

\section{Pharmacology of $I_{\text {to1 }}$}

4-AP is the first compound used by Kenyon and Gibbon to separate $\mathrm{I}_{\mathrm{to} 1}$ from $\mathrm{I}_{\mathrm{to} 2}$ (or $\mathrm{I}_{\mathrm{Ca} . \mathrm{Cl}}$ ) in sheep Purkinje fibers (Kenyon and Gibbons, 1979). It is then widely employed as a pharmacological tool to separate $\mathrm{I}_{\text {to1 }}$ from other currents (Li et al., 1995). $\mathrm{I}_{\text {tol }}$ is a major repolarization current in human atrium. The blockade of $\mathrm{I}_{\text {tol }}$ is supposed to prolong atrial APD and the refractory period and therefore exert anti-arrhythmic effect. Several antiarrhythmic drugs inhibit $\mathrm{I}_{\mathrm{tol}}$ in human atrial myocytes (see review by Tamargo et al., 2004). The class I anti-arrhythmic drug flecainide blocks inactivated $\mathrm{I}_{\mathrm{tol}}$ in a frequency-independent manner (Wang et al., 1995), and quinidine shows an open channel blocker of $\mathrm{I}_{\mathrm{tol}}$ in a frequency-dependent manner. Propafenone blocks human atrial $\mathrm{I}_{\mathrm{tol}}$ in a voltage- and use-independent fashion (Seki et al., 1999). Ambasilide inhibits $\mathrm{I}_{\mathrm{tol}}$ without affecting voltage-dependence of activation, inactivation, or recovery from inactivation, but accelerates the inactivation of $\mathrm{I}_{\text {tol }}$, suggesting an open-channel block (Feng et al., 1997).

In addition, $\mathrm{Ca}^{2+}$ channel antagonists (diltiazem and nifedipine) inhibit $\mathrm{I}_{\mathrm{tol}}$ in human atrial myocytes (Gao et al., 2005). Raloxifene, a selective estrogen receptor modulator, directly inhibits human atrial $\mathrm{I}_{\text {tol }}$ (Liu et al., 2007). The antifungal antibiotic clotrimazole inhibits $\mathrm{I}_{\text {tol }}$ by accelerating the inactivation and slowing 
the recovery from inactivation of the channels (Tian et al., 2006). The antihistamine drug loratadine rate-dependently inhibits $\mathrm{I}_{\text {to1 }}$ at a therapeutic concentration $(10 \mathrm{nM})$ (Crumb, 1999). The omega-3 (n-3) polyunsaturated fatty acids EPA (eicosapentaenoic acid) and DHA (docosahexaenoic acid) from fish oil inhibit human atrial $\mathrm{I}_{\mathrm{tol}}$ in a concentration-dependent manner (Li et al., 2009) (Table 1).

\section{The ultra-rapidly delayed rectifier $\mathrm{K}^{+}$current $\mathrm{I}_{\mathrm{Kur}}$}

$\mathrm{I}_{\mathrm{Kur}}$ is a rapid activation and slow inactivation $\mathrm{K}^{+}$current (Snyders et al., 1993; Wang et al., 1993). It is functionally present in the atria but not in the ventricles of human heart ( $\mathrm{Li}$ et al., 1996). $\mathrm{I}_{\mathrm{Kur}}$ is thought to be a promising molecular target for atrial arrhythmia (Ford and Milnes, 2008; Kozlowski et al., 2009; Tamargo et al., 2009). $I_{K u r}$ is also observed in canine (Fedida et al., 2003; Yue et al., 1996), pig (Li et al., 2004) and rat (Boyle and Nerbonne, 1992) atrial myocytes.

\section{A. Molecular identification of $\mathbf{I}_{\mathrm{Kur}}$}

Kv1.5 (KCNA5) encodes the pore-forming subunit of human atrial $\mathrm{I}_{\text {Kur }}$ (Snyders, 1999; Fedida et al., 1993), which is supported by the evidence that Kv1.5 antisense oligodeoxynucleotides specifically inhibits $\mathrm{I}_{\mathrm{Kur}}$ density in human atrial myocytes (Feng et al., 1997), and Kv1.5 gene is significantly expressed in human atrium (Gaborit et al., 2007). In canine atrium, $\mathrm{I}_{\mathrm{Kur}}$ is initially found to be encoded by Kv3.1 (Yue et al., 1996); however, a later study confirms that Kv1.5 does encode the $\mathrm{I}_{\mathrm{Kur}}$ in canine atrial myocytes (Fedida et al., 2003). The finding of the later study makes it possible to use canine model in evaluating $\mathrm{I}_{\mathrm{Kur}} / \mathrm{Kv} 1.5$ blockers for the treatment of AF ( $\mathrm{Li}$ et al., 2008). In addition, Kv1.5 mRNA and protein, responsible for $\mathrm{I}_{\mathrm{Kur}}$, are present in mouse and rat hearts (Nerbonne, 2000). Moreover, Kv1.5 transcripts are also detected in extracardiac tissues, e.g. pituitary gland, brain, pancreas, etc (Takimoto et al., 1993).

Multiple members of a Kv $\beta 1$ subunit family for Kv1.5 have been cloned and multiple N-terminal splice isoforms were detected (Snyders, 1999). Kv $\beta 1$ encodes the ancillary subunit (Martens et al., 1999) of $I_{K u r}$ channels. Co-expression of accessory $\mathrm{Kv} \beta$-subunits $(\mathrm{Kv} \beta-1.2 / 1.3)$ increases the inactivation of Kv1.5 channels and the sensitivity to channel phosphorylation by PKA and/or PKC (Kwak et al., 1999).

In chronic AF, $\mathrm{I}_{\mathrm{Kur}}$ density, Kv1.5 mRNA and protein (like other ion currents, including $\mathrm{I}_{\text {tol }}, \mathrm{I}_{\mathrm{Ca} . \mathrm{L}}$, and $\mathrm{I}_{\mathrm{Na}}$ ) are downregulated (Brundel et al., 2001; Grammer et al., 2000). Loss of function of mutant Kv1.5 channels however may lead to inheritable AF (Olson et al.). Loss-of-function mutations of KCNA5 gene located at the N-terminus (A115V), S1 (A251T), S1-S2 linker (P307S, P310L), and C-terminus (P532L and R578K) have been reported in patients with idiopathic AF (Simard et al., 2005). These findings suggest that defective Kv1.5 channels may predispose the atria to electrical instability and arrhythmogenesis.

\section{B. Signaling regulation of $\mathbf{I}_{\mathrm{Kur}}$}

$\beta$-adrenergic stimulation enhances, whereas $\alpha$-adrenergic stimulation inhibits $\mathrm{I}_{\mathrm{Kur}}$ in human atrial myocytes mediated by PKA and PKC, respectively (Li et al., 1996). However, in dog atrial myocytes, both $\beta$ - and $\alpha$-adrenergic stimulation increases $\mathrm{I}_{\mathrm{Kur}}$ by activating PKA and PKC (Yue et al., 1999). Whether the different regulation of $\mathrm{I}_{\mathrm{Kur}}$ by $\mathrm{PKC}$ is related to the non-uniform coding (Kv1.5 and Kv3.1) (Fedida et al., 2003; Yue et al., 1996) remains to be studied in canine atrial myocytes. PKA activation reduces the Kv $\beta$-induced fast inactivation of Kv1.5 channels by phosphorylating Kv $\beta$-subunit itself (Kwak et al., 1999). Nitric oxide inhibits hKv1.5 channels by a cGMP-dependent mechanism and by S-nitrosylating the channel protein (Nunez et al., 2006). Pyridine nucleotides modulate Kv1.5 channels by regulating the cellular redox state (NADPH-to-NADP ${ }^{+}$ratio) (Tipparaju et al., 2007). Moreover, phosphatidylinositol 4,5-bisphosphate (PIP2) regulates the inactivation of Kv1.5 by an equilibrium binding of the N-terminus of $\operatorname{Kv} \beta 1.3$ between phosphoinositides and the inner pore region of the channels (Decher et al., 2008).

\section{Pharmacology of $I_{K u r}$}

Human cardiac $\mathrm{I}_{\mathrm{Kur}}$ and/or Kv1.5 channels are sensitive to inhibition by 4-AP (Snyders et al., 1993; Wang et al., 1993), but not by tetraethylammonium (TEA) or $\mathrm{Ba}^{2+}$ (Wang et al., 1993). Low concentration of 4-AP (less than $50 \mu \mathrm{M}$ ) is used to separate $\mathrm{I}_{\mathrm{Kur}}$ from $\mathrm{I}_{\text {tol }}$ in human atrial myocytes (Feng et al., 1997; Li et al., 1996).

The compounds capable of $\mathrm{I}_{\mathrm{Kur}} / \mathrm{Kv} 1.5$ channel block are shown in Table 1 . Several antiarrhythmic drugs (see review, Tamargo et al., 2004), including quinidine, flecainide, and ambasilide inhibit $\mathrm{I}_{\mathrm{Kur}}$ in isolated human atrial myocytes (Feng et al., 1997; Wang et al., 1995) and/or Kv1.5 channel expressed in mammalian cells (Snyders and Yeola, 1995). The L-type $\mathrm{Ca}^{2+}$ channel antagonists verapamil, diltiazem and nifedipine reversibly inhibits human atrial $\mathrm{I}_{\mathrm{Kur}}$ (Gao et al., 2004; Gao et al., 2005). The local anesthetic drugs benzocaine and bupivacaine blocks Kv1.5 channels in a concentration-dependent manner (Caballero et al., 2002). The omega-3 polyunsaturated fatty acids also inhibit human atrial $\mathrm{I}_{\mathrm{Kur}}$ (Li et al., 2009) (Table 1).

The binding of these drugs is determined by an electrostatic component reflecting the electrical binding distance. The critical residues for hydrophobic binding of quinidine in hKv1.5 channels are located in the 
putative S6 of pore-lining region and is important in determining drug affinity and specificity (Snyders and Yeola, 1995). Stereoselective bupivacaine block of hKv1.5 channels is determined by a polar interaction with T507 and two hydrophobic interactions at positions L510 and V514 (Franqueza et al., 1997). The binding sites for quinidine and bupivacaine in the residues of the S6 segment also determine the binding of neutral and acid drugs (e.g. benzocaine) (Caballero et al., 2002; Tamargo et al., 2004). Nonetheless, the external mouth of the channel pore formed by the P-loop and adjacent S5-S6 segments is the potential binding sites for some drugs (Lin et al., 2001; Tamargo et al., 2004). Long-chain polyunsaturated fatty acids bind to an external site to block Kv1.5 channels (Honore et al., 1994).

AVE0118 is one of the most studied novel atrial-selective compounds (Table 1). It blocks human atrial $\mathrm{I}_{\text {Kur }}$ and Kv1.5 channels (Gogelein et al., 2004; Wettwer et al., 2004) by binding to T479, T480, V505, I508, V512, and V516 within the S6 domain and pore helix region (Decher et al., 2006), and prolongs the APD in atrial myocytes from patients with AF (Wettwer et al., 2004). AVE0118 also inhibits hKv4.3 channels expressed in $\mathrm{CHO}$ cells and $\mathrm{I}_{\mathrm{KACh}}$ in guinea pig atrial myocytes (Gogelein et al., 2004), which may contribute to the atrial-selective effects on APD and ERP (effective refractory period) (Christ et al., 2008). Importantly, AVE0118 terminates AF in a goat model with an intravenous administration (Blaauw et al., 2004; de Haan et al., 2006). However, AVE0118 has a low solubility and undergoes rapid first pass hepatic metabolism with a short half-life in dog and pig (intravenous administration, $\mathrm{T}_{1 / 2}=0.2-0.4$ hours) (Ford and Milnes, 2008; Wirth et al., 2007); therefore it has not progressed into phase 3 clinical trial for anti-AF (Ford and Milnes, 2008). AVE1231 is a chemically different compound with similar effects to those of AVE0118 (Ehrlich et al., 2008) on $\mathrm{I}_{\mathrm{Kur}} / \mathrm{Kv} 1.5, \mathrm{I}_{\mathrm{t}}, \mathrm{I}_{\mathrm{KACh}}$. It is orally effective and prolongs atrial ERP in pig and goat models with rapid pacing (Wirth et al., 2007). AVE1231 is undergoing phase 1 clinical trial (Ford and Milnes, 2008).

Diphenyl phosphine oxide (DPO) compounds selectively inhibit human atrial $\mathrm{I}_{\mathrm{Kur}}$ and hKv1.5 current without affecting $\mathrm{I}_{\text {tol }}$ or prolonging cardiac APD in human ventricular myocytes (Lagrutta et al., 2006). DPO-1 preferentially binds to the open channels of Kv1.5 with putative binding sites T480, L499, L506, I508, L510 and V514 (Du et al., 2010). DPO-1 significantly prolongs atrial ERP in African green monkeys (Regan et al., 2006) and terminates atrial arrhythmia in a canine atrial flutter model without increasing ventricular ERP or PR, QRS or QT interval of ECG (Stump et al., 2005).

ISQ-1 is an isoquinoline Kv1.5 channel blocker, prolongs atrial ERP in African green monkey and dogs, and terminates dog atrial flutter and/or AF (Regan et al., 2008; Regan et al., 2007). Vernakalant (RSD1235) blocks $\mathrm{I}_{\mathrm{Kur}} / \mathrm{Kv} 1.5$ current with a high affinity and binding to T479, T480, I502, V505, and V508 residues (Eldstrom et al., 2007; Fedida et al., 2005). It also inhibits the cardiac $\mathrm{I}_{\mathrm{to} 1}$, $\mathrm{I}_{\mathrm{KACh}} \mathrm{I}_{\mathrm{Kr}}$ and $\mathrm{I}_{\mathrm{Na}}$ at higher concentrations (Fedida, 2007; Fedida et al., 2005). Clinical trial has demonstrated that vernakalant converts AF rapidly without prolonging QT interval of ECG in patients (Fedida, 2007; Roy et al., 2004), it is under consideration by the FDA of USA for clinical use in treating patients with AF.

Acacetin is a natural flavone compound initially isolated from Chinese traditional medicine Xuelianhua (Saussurea tridactyla). It suppresses not only atrial $\mathrm{I}_{\mathrm{Kur}}$, but also $\mathrm{I}_{\mathrm{tol}}$ and $\mathrm{I}_{\mathrm{KACh}}$. Acacetin prolongs canine atrial ERP without prolonging QTc interval and effectively prevents AF in a canine model after duodenal administration ( $\mathrm{Li}$ et al., 2008), suggesting that acacetin may be orally effective.

\section{The rapidly delayed rectifier $\mathrm{K}^{+}$current $\mathrm{I}_{\mathrm{Kr}}$}

Sanguinetti and Jurkiewicz demonstrate that the class III antiarrhythmic drugs notably E-4031 and sotalol selectively block $\mathrm{I}_{\mathrm{Kr}}$ and that the drug-sensitive $\left(\mathrm{I}_{\mathrm{Kr}}\right)$ and drug-resistant $\left(\mathrm{I}_{\mathrm{Ks}}\right)$ components of $\mathrm{I}_{\mathrm{K}}$ differ in terms of voltage dependence, kinetics, rectification properties, and pharmacological sensitivity (Sanguinetti and Jurkiewicz, 1990). $\mathrm{I}_{\mathrm{Kr}}$ and $\mathrm{I}_{\mathrm{Ks}}$ play an important role in cardiac repolarization in different species including human ( $\mathrm{Li}$ et al., 1996). $\mathrm{I}_{\mathrm{Kr}}$ channels open rapidly upon depolarization of the action potential, but quickly inactivates. The channel inactivation is released following repolarization with a slow deactivation (Sanguinetti and Jurkiewicz, 1990). Due to this inward rectification property, $\mathrm{I}_{\mathrm{Kr}}$ contributes a little during the plateau of cardiac action potential, and progressively increases at phase 3 repolarization of the action potential (Fig. 1) (Jost et al., 2005). Therefore, $I_{\mathrm{Kr}}$ plays a pivotal role in cardiac repolarization, especially in the later phases of the action potential due to its unique kinetics (Fig. 1).

\section{A. Molecular identification of $\mathbf{I}_{\mathbf{K r}}$}

The human ether-a-go-go-related gene (hERG or Kv11.1, or KCNH2) coding for the channels carrying the current resembling $\mathrm{I}_{\mathrm{Kr}}$ has been identified in human heart (Sanguinetti et al., 1995), encodes the $\alpha$-subunit underlying human cardiac $\mathrm{I}_{\mathrm{Kr}}$, and is expressed in both atria and ventricles of human heart (Gaborit et al., 2007). Co-assembly of the regulatory $\beta$-subunit MiRP1 (minK-related peptide 1 encoded by KCNE2 gene) with $\mathrm{hERG} \alpha$-subunits is required to form native $\mathrm{I}_{\mathrm{Kr}}$ (Gordon et al., 2008).

Suppression of $\mathrm{I}_{\mathrm{Kr}} / \mathrm{hERG}$ channels by medications may cause acquired long QT syndrome (LQT) (Farkas and Nattel, 2010; Perrin et al., 2008). Therefore, potential hERG channel blockade has been a 
necessary screening procedure at the early stage of developing compounds (Dennis et al., 2007; Farkas and Nattel, 2010). Loss of function mutations of hERG and KCNE2 gene induces congenital LQT2 and LQT6, respectively, which are characterized in patients by prolonged QT interval of ECG, abnormal T waves and a risk of fatal ventricular arrhythmias named Torsades de Pointes (TdPs) (Perrin et al., 2008; Thomas et al., 2006). However, on the other hand, gain of function mutations of hERG (McPate et al., 2009) is responsible for inherited short QT syndrome (SQT1), which is characterized in patients by abnormally short QT interval, and a high risk of atrial/ventricular fibrillation and sudden death (Brugada et al., 2004; Charpentier et al., 2010).

\section{B. Signaling regulation of $\mathbf{I}_{\mathrm{Kr}}$}

Although it is generally accepted that $\mathrm{I}_{\mathrm{Kr}}$ and/hERG channels are relatively insensitive to signaling modulation, a list of signaling molecules have been reported to regulate $\mathrm{I}_{\mathrm{Kr}} / \mathrm{hERG}$ channels, including cAMP, PKA, PKC, PIP2, etc. (see review, Charpentier et al., 2010). Activation of $\beta$ - or $\alpha$-adrenergic receptor suppresses hERG channels by increasing intracellular cAMP levels. PKA decreases the current amplitude, accelerates the deactivation and positively shifts the activation conductance via phosphorylating the hERG channel protein. On the other hand, intracellular cAMP may increase the current by directly binding to the cyclic nucleotide binding domain in C-terminus of hERG channels and negatively shifting the activation conductance (Thomas et al., 2006).

PIP2 up-regulates hERG current by accelerating the activation and slowing the inactivation of the channels (Bian et al., 2004). The polycationic region in C-terminus of hERG channels is the potential electrostatic interaction sites of PIP2 (Bian et al., 2004). Stimulation of $\alpha-1_{\mathrm{A}}$ adrenoceptor decreases $\mathrm{hERG}$ current and positively shifts the activation conductance, which is related to the consumption of endogenous PIP2 induced by PLC (phospholipase C) activation (Bian et al., 2004). In addition, hERG channels are also constitutively activated by Src-family kinases and EGFR kinase via phosphorylating the tyrosine residues Y475 and/or Y611 (Zhang et al., 2008). Moreover, nitric oxide inhibits hERG current via an interaction with free radical oxygen species in a cyclic GMP-independent manner (Taglialatela et al., 1999).

A recent study demonstrates that chronic hypokalemia rabbits exhibit a prolonged QT interval of ECG, and a downregulated $\mathrm{I}_{\mathrm{Kr}}$ without significantly affecting other membrane current in ventricular myocytes isolated from the hypokalemia rabbits. Further investigation indicates that a reduced extracellular $\mathrm{K}^{+}$ decreases the current amplitude, plasma membrane stability, and expression of hERG channel protein by accelerating internalization and degradation of hERG channels (Guo et al., 2009). This study reveals the potential mechanism why hypokalemia patients are susceptible to LQTs and TdPs tachyarrhythmias (Roden et al., 1986).

\section{Pharmacology of $\mathbf{I}_{\mathbf{K r}}$}

$\mathrm{I}_{\mathrm{Kr}} / \mathrm{hERG}$ channels are extraordinarily sensitive to block by a large number of structurally diverse drugs/chemicals (Farkas and Nattel, 2010; Raschi et al., 2009). $\mathrm{I}_{\mathrm{Kr}} / \mathrm{hERG}$ blockers such as quinidine, d-sotalol, dofetilide, etc. have been used for many years as class III antiarrhythmic drugs, and they are efficacious in preventing and terminating $\mathrm{AF}$ and flutter, but their intrinsic arrhythmogenic activity largely restricts their use due to the well-known major effect of inducing LQTs and TdPs, a substrate of life-threatening ventricular arrhythmia. Therefore, the class III antiarrhythmic drugs with $\mathrm{I}_{\mathrm{Kr}} / \mathrm{hERG}$ channel block are not an ideal medication used for treating AF.

In addition to class III antiarrhymic drugs, many other commonly used clinical medications also block human $\mathrm{I}_{\mathrm{Kr}}$ and hERG channels (see review, Tamargo et al., 2004), for example (Table 1), the antihistamine drugs terfenadine and loratadine (Crumb, 2000), the antiestrogenic drugs tamoxifen (Thomas et al., 2003) and clomiphene (Yuill et al., 2004), the antifugal drug ketoconazole (Takemasa et al., 2008), the antihypertensive drug ketanserin (Tang et al., 2008) and the antipsychotic drug ziprasidone (Su et al., 2006). These drugs preferentially block the open hERG channels, but also exhibit low affinity for closed and inactivated channels (Tristani-Firouzi and Sanguinetti, 2003). The hERG channel inhibition of the non-antiarrhythmic drugs is the major cause of life-threatening proarrhythmia. This has directly prompted the withdrawal of several clinical drugs from the market (Thomas et al., 2006). Regulatory Agencies therefore request that all new drug candidates be tested for this possibility.

The binding sites of hERG channel blockers are located within the inner cavity of hERG channels. The individual residues that form high-affinity and lower-affinity binding sites have been identified by site-directed mutagenesis approaches, and the gating processes have an important influence on the drug-binding sites (Mitcheson, 2008). The S620 in pore helix of hERG channels is the binding site of dofetilide and verapamil, and an intact C-type inactivation process is also crucial for high-affinity drug binding (Ficker et al., 1998; Zhang et al., 1999). The binding sites of high-affinity hERG blocker MK-499 are located on S6 transmembrane domain (G648, Y652 and F656) and pore helix (T623 and V625) of the 
hERG channels that face the vestibule of the channels. Compounds structurally unrelated to MK-499, such as terfenadine and cisapride, also interact with Y652 and F656, but not with V625 (Mitcheson, J. et al., 2005). However, the binding site of propafenone (a lower-affinity hERG blocker) is located in the F656 residue alone (Witchel et al., 2004). When the drug binds within the inner cavity of the channels, they are trapped in the vestibule by closure of the activation gate upon repolarization. So hERG channel blockers such as the methanesulfonanilides MK-499 show a slow recovery from blockade (Mitcheson et al., 2005).

In addition to the direct channel block by binding to the $h E R G$ channels, some drugs suppress $I_{K r} / h E R G$ channels and induced acquired long QT syndrome in patients by interrupting the trafficking of hERG channels and reducing the expression of membrane hERG channel protein. The anti-protozoal drug pentamidine is one of examples (Kuryshev et al., 2005). To rescue LQTs, a number of compounds have been developed for activating $\mathrm{I}_{\mathrm{Kr}} / \mathrm{hERG}$ channels (Table 1 ).

RPR260243 is the first small molecule that activates $\mathrm{I}_{\mathrm{Kr}} / \mathrm{hERG}$ channels. It dramatically slows the deactivation of hERG tail current in a CHO cell line expressing hERG gene. PR260243 reverses the action potential-prolonging effect by dofetilide in guinea pig ventricular myocytes and reduced QT interval of ECG in perfused guinea pig hearts (Kang et al., 2005).

Several potent hERG channel activators developed by Pfizer (Groton, CT) are reported with a distinct mechanism (Zhou et al., 2005). PD-118057 enhances hERG step and tail currents in a HEK 293 stable cell line in a concentration-dependent manner and is able to prevent and reverse QT prolongation and associated arrhythmias induced by a selective $\mathrm{I}_{\mathrm{Kr}}$ blocker (i.e.dofetilide) in the arterially perfused rabbit ventricular wedge preparation (Zhou et al., 2005).

NS1643 and NS3623 developed by NeuroSearch A/S (Ballerup, Denmark) increases WT hERG current by reducing channel inactivation, while reducing the activation in inactivation-deficient hERG mutants (S620T, S631A) (Hansen et al., 2006). Interestingly, mutation of the high-affinity binding site F656 for hERG channel blocker strengthens the agonist activity of NS1643 and NS3623, suggesting a dual mode of action, being both an activator and an inhibitor of hERG channels (Hansen et al., 2006).

A-935142 is a recently developed compound by Abbott Laboratories (Abbott Park, IL) with significant hERG enhancement by facilitating activation, reducing inactivation, and slowing deactivation of the channels. It shortens cardiac APD in guinea-pig atrial myocytes and canine Purkinje fibers (Su et al., 2009).

The putative binding sites for RPR260243 are located in S5 (L553 and F557) and an adjacent region of S6 (N658, V659) (Perry et al., 2007), while the binding sites of PD-118057 are located in the pore helix (F619) or the S6 segment (L646). Interestingly, the mutants of nearby residues in the S6 segment (C643, M645) enhance the drug activity of PD-118057 (Perry et al., 2009). In contrast, PD-307243, an analog of PD-118057, increases hERG current by remarkably slowing hERG channel deactivation and inactivation and holding the channels in a constitutively open state via binding to the extracellular region of the pore (Gordon et al., 2008).

3-Nitro- $N$-(4-phenoxyphenyl) benzamide (ICA-105574) is an unique and potent hERG channel activator more recently developed by Icagen (Durham, NC) (Gerlach et al., 2010). It steeply increases the hERG current amplitudes by removing the inwardly-rectifying inactivation of the channels, negatively shifting the voltage-dependence of channel activation and slowing channel deactivation. It shortens cardiac APD in ventricular myocytes from guinea pig hearts (Gerlach et al., 2010).

\section{The slowly delayed rectifier $\mathrm{K}^{+}$current $\mathrm{I}_{\mathrm{Ks}}$}

$\mathrm{I}_{\mathrm{Ks}}$ activates slowly with almost no inactivation after activation (Charpentier et al., 2010; Sanguinetti and Jurkiewicz, 1990), and contributes to the phase 2 slow repolarization of cardiac action potential (Fig. 1). $\mathrm{I}_{\mathrm{Ks}}$ has been demonstrated in cardiac tissues/myocytes from different species including human (Charpentier et al., 2010; Jost et al., 2005; $\mathrm{Li}$ et al., 1996). The physiological contribution of $\mathrm{I}_{\mathrm{Ks}}$ to the human ventricular action potential is limited; however, during tonic sympathetic stimulation or when cardiac repolarization reserve is attenuated, $\mathrm{I}_{\mathrm{Ks}}$ plays an important role in limiting APD prolongation due to its slow deactivation (Jost et al., 2005).

Heterogeneous expression of $\mathrm{I}_{\mathrm{Ks}}$ is present in different regions of the heart. In the canine ventricle, $\mathrm{I}_{\mathrm{Ks}}$ density is greater in epicardial and endocardial cells than in the M cells (Li et al., 2002; Liu and Antzelevitch, 1995). The lower $\mathrm{I}_{\mathrm{Ks}}$ density in M cells is considered to be related to the steeper APD-rate relations and their greater tendency to display longer APD and to develop EADs at slow heart rates or in response to QT prolonging drugs (Liu and Antzelevitch, 1995).

\section{A. $\mathbf{I}_{\mathrm{Ks}}$ molecular identification}

$\mathrm{I}_{\mathrm{Ks}}$ channels are comprised of four pore-forming $\alpha$-subunits and two accessory $\beta$-subunits, which are encoded by KCNQ1 (Kv7.1 or KvLQT1) and KCNE1 (minK) genes respectively (Barhanin et al., 1996; Sanguinetti et al., 1996). The cytoplasmic C-terminus of KCNQ1 subunit contains a tetramer assembly domain, in which mutations lead to tetramerization deficiency. The KCNE1 subunit dynamically engages in 
$\mathrm{I}_{\mathrm{Ks}}$ gating, and is critical for the biophysical properties of the native cardiac $\mathrm{I}_{\mathrm{Ks}}$ (Charpentier et al., 2010; Sanguinetti et al., 1996).

$\mathrm{I}_{\mathrm{Ks}}$ density is down-regulated in failing canine ( $\mathrm{Li}$ et al., 2002) and human (Li et al., 2004) hearts. A decreased $\mathrm{I}_{\mathrm{Ks}}$ and KCNQ1/KCNE1 mRNA levels are found in cardiac myocytes from infarcted canine ventricle (Jiang et al., 2000). Loss of function mutations in KCNQ1 gene and KCNE1 gene are associated with congenital LQT1 and LQT5, respectively (Charpentier et al., 2010; Splawski et al., 1997). However, gain of function mutations in KCNQ1 gene causes congenital SQT2 and familial AF (Charpentier et al., 2010; Lundby et al., 2007).

\section{B. Signaling regulation of $\mathbf{I}_{\mathrm{Ks}}$}

It is well established that catecholamines shorten cardiac APD by enhancing $\mathrm{I}_{\mathrm{Ks}}$ amplitude mediated by cAMP/PKA and/or PKC via $\beta$ - and/or $\alpha$-adrenoceptor stimulation (Sanguinetti et al., 1991; Walsh and Kass, 1991). Activation of PKA by cAMP or phophodiesterase inhibition increases $I_{K s}$ current and enhances the rate-dependent shortening of cardiac APD (Lo and Numann, 1998; Terrenoire et al., 2005). $\mathrm{I}_{\mathrm{Ks}}$ is also modulated by EGFR kinase (Dong et al., 2010). In addition, $\mathrm{I}_{\mathrm{Ks}}$ or KCNQ1/KCNE1 channels are regulated by CaMKII, nitric oxide, and PIP2, etc. Readers are recommended to refer to the recent review (Charpentier et al., 2010) for the detailed information of $\mathrm{I}_{\mathrm{Ks}}$ regulation.

\section{Pharmacology of $I_{K s}$}

Chromanols (e.g. 293B, HMR-1556) are the first group of relatively selective $\mathrm{I}_{\mathrm{Ks}}$ blockers (Busch et al., 1996; Thomas et al., 2003) (Table 1), and show stereospecific block on $\mathrm{I}_{\mathrm{Ks}}$ (Yang et al., 2000). Indapamide (Turgeon et al., 1994) and benzodiazepine compounds (L-735821, L-761334, etc) (Lengyel et al., 2001; Seebohm et al., 2003; Stump et al., 2003) also remarkably block $\mathrm{I}_{\mathrm{Ks}}$. Most of them act as open channel blockers. Bepridil, a Ca ${ }^{2+}$ channel blocker, inhibits recombinant cardiac $\mathrm{I}_{\mathrm{Ks}}$ by binding to the closed state channels (Yumoto et al., 2004). The drug interaction site of $\mathrm{I}_{\mathrm{Ks}}$ blockers (e.g. 293B and L-735821) is located in the pore loop and S6 domain of KCNQ1. T312 in the pore loop and I337, P339, P340, and A344 in the S6 domain are the most important molecular determinants of channel block (Seebohm et al., 2003).

Blockade of $\mathrm{I}_{\mathrm{Ks}}$ usually fails to remarkably prolong cardiac APD due to the sufficient repolarization reserve carried by other $\mathrm{K}^{+}$channels (Lengyel et al., 2001). However, when the repolarization reserve is attenuated or depleted by inherited disorders, cardiac electrical remodeling or drugs, blockade of $\mathrm{I}_{\mathrm{Ks}}$ significantly prolongs the ventricular APD (Biliczki et al., 2002). Moreover, $\beta$-adrenergic stimulation increases $\mathrm{I}_{\mathrm{Ks}}$ in epicardial and endocardial cells, but not in $\mathrm{M}$ cells. $\mathrm{I}_{\mathrm{Ks}}$ is intrinsically small, and $\mathrm{I}_{\mathrm{Ks}}$ block accentuates transmamural dispersion of repolarization (Shimizu and Antzelevitch, 1998). Similar to the $\mathrm{I}_{\mathrm{Kr}}$ blocker, the $\mathrm{I}_{\mathrm{Ks}}$ blocker is also proarrhythmic (Cheng and Incardona, 2009). Therefore, $\mathrm{I}_{\mathrm{Ks}}$ activators, like $\mathrm{I}_{\mathrm{Kr}}$ activators, may be useful in managing the cardiac arrhythmia related to delayed repolarization.

The $\mathrm{Cl}^{-}$channel blockers mefenamic acid and dihydro-4,4' diisothiocyanostilbene-2,2'- disulphonic acid (DIDS) are the first group compounds (Table 1) that enhance the recombinant $\mathrm{I}_{\mathrm{Ks}}$ by reversibly speeding up channel activation in a KCNE1 subunit-dependent manner (Unsold et al., 2000). Thereafter, the novel benzodiazepine compound R-L3 is found to enhance cardiac $\mathrm{I}_{\mathrm{Ks}}$ or recombinant $\mathrm{I}_{\mathrm{Ks}}$. R-L3 stereospecifically activates $\mathrm{I}_{\mathrm{Ks}}$ and shortens APD in guinea pig cardiac myocytes by slowing the rate of $\mathrm{I}_{\mathrm{Ks}}$ deactivation and negatively shifting the activation conductance of $\mathrm{I}_{\mathrm{Ks}}$ (Salata et al., 1998). The interaction sites of R-L3 with $\mathrm{I}_{\mathrm{Ks}}$ channels are located in the S5 and S6 domains of KCNQ1 subunits (Seebohm et al., 2003).

Several natural compounds are recently demonstrated to up-regulate native cardiac $\mathrm{I}_{\mathrm{Ks}}$ and/or recombinant $\mathrm{I}_{\mathrm{Ks}}$. Tanshinone IIA is one of major active components from the Chinese traditional medicinal herb Danshen (Salvia miltiorrhiza ), and directly increases recombinant $\mathrm{I}_{\mathrm{Ks}}$ by accelerating the activation of the channels, and negatively shifting the activation conductance (Sun et al., 2008). Ephedrine, an alkaloid isolated from the Chinese traditional medicinal herb Mahuang (Ephedra Sinica) activates recombinant $\mathrm{I}_{\mathrm{Ks}}$, and negatively shifts the activation conductance. The binding sites of ephedrine on recombinant $\mathrm{I}_{\mathrm{Ks}}$ are located in the P-loop helix F296 and Y299 of KCNQ1 (Jing et al., 2009). Ginsenoside Re, a major ingredient of Panax ginseng, enhances $\mathrm{I}_{\mathrm{Ks}}$ via s-nitrosylating the channel protein mediated by nitric oxide in guinea-pig cardiomyocytes (Bai et al., 2004). Moreover, various fatty acids, including docosahexaenoic acid, lauric acid and oleic acid augment $\mathrm{I}_{\mathrm{Ks}}$ in a KCNE1 subunit-dependent manner (Doolan et al., 2002), and phenylboronic acid is also found to activate recombinant $\mathrm{I}_{\mathrm{Ks}}$ (Mruk and Kobertz, 2009).

$\mathrm{I}_{\mathrm{Ks}}$ activators, like the selective $\mathrm{I}_{\mathrm{Kr}} / \mathrm{hERG}$ activators, may also offer a new approach in the treatment of delayed repolarization conditions in patients with acquired long QT syndrome or inherited long QT syndrome. The $\mathrm{I}_{\mathrm{Ks}}$ activator benzodiazepine R-L3 displays a prominent antiarrhythmic propensity in rescuing cellular models with acquired long QT type 2 (Nissen et al., 2009).

\section{Inward rectifier $\mathrm{K}^{+}$currents}




\section{The cardiac inward rectifier $\mathrm{K}^{+}$current $\mathbf{I}_{\mathbf{K} 1}$}

Cardiac $I_{K 1}$ is a strong inward rectification current, and is believed to contribute only to the phase 3 rapid repolarization of action potential and maintain resting membrane potential in cardiac myocytes (Anumonwo and Lopatin, 2010). However, our recent studies have demonstrated that two components of $I_{K 1}$ are activated during cardiac action potential, one is immediately activated by action potential depolarization, and the other is activated at phase 3 repolarization. The $\mathrm{I}_{\mathrm{K} 1}$ activated by depolarization with comparable time course with $\mathrm{I}_{\mathrm{Na}}$ may also contribute to the maintenance of cardiac excitability (Fig. 1) (Li et al., 1998; Zhang et al., 2009). Thus, $\mathrm{I}_{\mathrm{K} 1}$ plays important roles in stabilizing the resting membrane potential, controlling cardiac APD and excitability (Anumonwo and Lopatin, 2010). $\mathrm{I}_{\mathrm{K} 1}$ density is higher in ventricular than in atrial myocytes, but there is no difference in regional cells through ventricular wall in canine and guinea pig hearts (Schram et al., 2002), and is very low in SA and AV pacemaker cells, and therefore these cells have a more depolarized maximum diastolic potential (Schram et al., 2002).

\section{A. Molecular identification of $\mathbf{I}_{\mathbf{K} 1}$}

Cardiac $\mathrm{I}_{\mathrm{K} 1}$ is encoded by Kir2.1 (KCNJ2), Kir2.3 (KCNJ4), and/or Kir2.2 (KCNJ12) (Dhamoon et al., 2004; Ehrlich, 2008). Heteromeric assemblies of Kir2.1, Kir2.2, and Kir2.3 subunits underlie $\mathrm{I}_{\mathrm{K} 1}$ current. The unique properties of individual Kir2 isoforms, as well as their region- and species-dependent expression patterns determine the heterogeneous profiles of $\mathrm{I}_{\mathrm{K} 1}$ in atrial and ventricular myocytes of the heart (Dhamoon et al., 2004).

Cardiac $\mathrm{I}_{\mathrm{K} 1}$ is altered under different pathophysiological conditions. $\mathrm{I}_{\mathrm{K} 1}$ is downregulated in ventricular myocytes from failing canine (Li et al., 2002) and human (Li et al., 2004) hearts, but no Kir2.1 mRNA reduction is observed (Koumi et al., 1995). In atrial myocytes from patients with chronic AF $\mathrm{I}_{\mathrm{K} 1}$ is up-regulated (Dobrev et al., 2002), which may be related to the selective S-nitrosylation of Kir2.1 Cys76 residue by nitric oxide (Gomez et al., 2009).

Loss of function mutation of KCNJ2 causes inherited Andersen-Tawil syndrome (LQT7), which is characterized by periodic paralysis, specific T-U-wave patterns, and skeletal developmental abnormalities (Anumonwo and Lopatin, 2010; Zhang et al., 2005). On the other hand, gain of function mutation of KCNJ2 causes inherited SQT3 and familial AF (Anumonwo and Lopatin, 2010; Priori et al., 2005; Xia et al., 2005).

\section{B. Signaling regulation of $\mathbf{I}_{\mathbf{K} 1}$}

It is well recognized that the conductance of $\mathrm{I}_{\mathrm{K} 1}$ is highly dependent on extracellular $\mathrm{K}^{+}$concentration. An increase in extracellular $\mathrm{K}^{+}$concentration enhances the conductance of $\mathrm{I}_{\mathrm{K} 1}$, while the conductance disappears with removal of extracellular $\mathrm{K}^{+}$(Li et al., 1998; Zhang et al., 2009). $\mathrm{I}_{\mathrm{K} 1}$ is uniquely blocked by intracellular polyamines (spermine, spermindine and putrescine) and $\mathrm{Mg}^{2+}$ with steep voltage dependence, which is believed to be the molecular mechanism of the inward rectification of $\mathrm{I}_{\mathrm{K} 1}$ (Anumonwo and Lopatin, 2010; Lopatin et al., 1994). However, the conclusion is made under symmetrical $\mathrm{K}^{+}$conditions. Under physiological $\mathrm{K}^{+}$conditions, an increase of intracellular $\mathrm{Mg}^{2+}$ concentration does not induce any block of $\mathrm{I}_{\mathrm{K} 1}$. instead of an increase in the transient outward component of $I_{K 1}$ (Zhang et al., 2009).

Both $\alpha$ - and $\beta$-adrenergic stimulation suppress $\mathrm{I}_{\mathrm{K} 1}$ in a PKA and/or PKC-dependent way (Karle et al., 2002; Koumi et al., 1995). PIP2 activates $\mathrm{I}_{\mathrm{K} 1}$ via direct electrostatic interaction between the positively charged residues in the cytoplasmic region of the channels and the negative phosphate head group of PIP2 (Xie et al., 2008). PIP2 is also an important co-factor of other regulators that modulate $\mathrm{I}_{\mathrm{K} 1}$ channels (Xie et al., 2007). Kir2 channels are down-regulated by membrane cholesterol level (Levitan, 2009). The extracellular $\mathrm{H}^{+}$regulates $\mathrm{I}_{\mathrm{K} 1}$ in species/tissue-dependent manner, possibly reflecting channel subunit composition (Anumonwo and Lopatin, 2010). Tyrosine kinase activation reduces the membrane density of Kir2.1 channels via promoting channel endocytosis (Tong et al., 2001).

In addition, Kir2.1 channels are post-transcriptionally suppressed by miRNA-1 in ischemia/reperfusion myocardium (Yang et al., 2007). The great reduction of miRNA-1 levels may also contribute to the up-regulation of Kir2.1 subunits and the increased $\mathrm{I}_{\mathrm{K} 1}$ in patients with AF (Girmatsion et al., 2009).

\section{Pharmacology of $\mathbf{I}_{\mathrm{K} 1}$}

$\mathrm{Ba}^{2+}$ is a well-known $\mathrm{I}_{\mathrm{K} 1}$ blocker with an $\mathrm{IC}_{50}$ of $20 \mu \mathrm{M}$ (Wible et al., 1995) (Table 1). Some antiarrhythmic drugs, such as amiodarone and azimilide, show an inhibitory effect on $\mathrm{I}_{\mathrm{K} 1}$ (see review, Tamargo et al., 2004). Blockade of $\mathrm{I}_{\mathrm{K} 1}$ may cause cardiac diastolic (i.e. resting membrane potential) depolarization, an proarrhythmic effect that offsets the membrane potential more close to the threshold potential of $\mathrm{Na}^{+}$ channels therefore reduces cardiac excitability. $\mathrm{I}_{\mathrm{K} 1}$ block also slows conduction velocity due to a voltage-dependent inactivation of $\mathrm{Na}^{+}$channels, and prolongs the QT interval (Kleber, 1994). Therefore the drug that specifically blocks $\mathrm{I}_{\mathrm{K} 1}$ may not be realistic for antiarrhthima. The compound RP58866 is initially designed to specifically block $\mathrm{I}_{\mathrm{K} 1}$, and is effective in treating ventricular arrhythmias induced by ischemia/reperfusion in rat, rabbit, and primate (Rees and Curtis, 1993). Later studies demonstrate that 
RP58866 is a non-selective $\mathrm{K}^{+}$channel blocker. In addition to inhibition of $\mathrm{I}_{\mathrm{K} 1}$, RP58866 also suppresses $\mathrm{I}_{\mathrm{to} 1}$, $\mathrm{I}_{\mathrm{Kr}}, \mathrm{I}_{\mathrm{Ks}}$, and $\mathrm{I}_{\mathrm{KACh}}$ (Brandts et al., 2000; Yang et al., 1999).

\section{The acetylcholine-activated $\mathrm{K}^{+}$current $\mathrm{I}_{\mathrm{KACh}}$}

Cardiac $\mathrm{I}_{\mathrm{KACh}}$ is one of $\mathrm{G}$ protein-coupled inwardly-rectifying $\mathrm{K}^{+}$channels. It is predominantly present in sinus node, atrial myocardium, and atrioventricular node, but largely sparse in ventricles of the heart (Dobrzynski et al., 2001; Gaborit et al., 2007; Schram et al., 2002). Activation of $\mathrm{I}_{\mathrm{KACh}}$ by parasympathetic signals such as acetylcholine through M2 muscarinic receptors causes an inward rectifier $\mathrm{K}^{+}$current which hyperpolarizes the membrane potential, shortens cardiac APD, slows the spontaneous firing rate of pacemaker cells in sinus and atrial-ventricular nodes, and delays the atrioventricular conduction (Ehrlich, 2008; Tamargo et al., 2004). The heterogeneity of $\mathrm{I}_{\mathrm{KACh}}$ expression within and between the left and right atria correlates with potentially proarrhythmic ability of vagal nerve stimulation (Arora et al., 2007). In addition, $\mathrm{I}_{\mathrm{KACh}}$ plays an important role in the generation of AF (Atienza et al., 2006).

\section{A. Molecular identification of $\mathbf{I}_{\mathrm{KACh}}$}

$\mathrm{I}_{\mathrm{KACh}}$ channel in the heart is a heterotetramer constituted by two Kir3.1 (KCNJ3/GIRK1) and two Kir3.4 (KCNJ5/GIRK4) subunits (Anumonwo and Lopatin, 2010; Corey et al., 1998).

$\mathrm{I}_{\mathrm{KACh}}$ is remodeled in heart disorders (Borlak and Thum, 2003; Brundel et al., 2001). $\mathrm{I}_{\mathrm{KACh}}$ current is transcriptionally down-regulated in chronic AF, but an agonist-independent (i.e., active in the absence of agonist) constitutively active form of $\mathrm{I}_{\mathrm{KACh}}$ contributes to human chronic AF (Dobrev et al., 2005; Voigt et al., 2007). Loss of function mutation of Kir3.4 gene is detected in, but not associated with clear atrial disorders (Calloe et al., 2007).

\section{B. Signaling regulation of $\mathbf{I}_{\mathrm{KACh}}$}

In addition to the acetylcholine-muscarinic receptor- $G$ protein pathway, cardiac $\mathrm{I}_{\mathrm{KACh}}$ may be activated by other G-protein coupled receptors including A1-adenosine, $\alpha$-adrenergic, etc. Adenosine activates rat atrial $\mathrm{I}_{\mathrm{KACh}}$ (Bosche et al., 2003). Activation of $\alpha 1$-adrenoceptor reduces $\mathrm{I}_{\mathrm{KACh}}$ current in atrial myocytes (Anumonwo and Lopatin, 2010). In canine atrial cardiomyocytes, $\beta 1$-adrenergic stimulation enhances $\mathrm{I}_{\mathrm{KACh}}$ current via cAMP-induced activation of PKA whereas $\alpha 1_{\mathrm{A}}$-adrenergic stimulation suppresses $\mathrm{I}_{\mathrm{KACh}}$ current via PLC-mediated activation of PKC (Yeh et al., 2007). PIP2 up-regulates $\mathrm{I}_{\mathrm{KACh}}$ in diverse manners: direct interaction with the channels or with $G \beta / \gamma$ subunits, and via the downstream PKC action (Keselman et al., 2007). Recombinant Kir3.1/Kir3.4 channels are regulated by PKA phosphorylation. Three phosphorylation sites (Ser385, ser401 and thr407) located within the C-terminus of Kir3.1 are responsible for PKA phosphorylation and the regulation of $I_{\mathrm{KACh}}$ channels (Mullner et al., 2009). G $\beta / \gamma$ also affects the trafficking of $\mathrm{I}_{\mathrm{KACh}}$ channels by forming $\mathrm{G} \beta / \gamma$-Kir3.1/Kir3.4 complexes during channel biosynthesis and trafficking (Robitaille et al., 2009).

\section{Pharmacology of $\mathbf{I}_{\mathrm{KACh}}$}

The atrial-specific localization and the functionally upregulation (increased constitutive activity) of $\mathrm{I}_{\mathrm{KACh}}$ during AF make it possible a promising antiarrhythmic target devoid of ventricular side effects (Ehrlich, 2008; Kozlowski et al., 2009). Much effort is made to develop selective $I_{\text {KACh }}$ blockers (Dobrev and Nattel, 2010) (Table 1).

Tertiapin, a 21-residue peptide toxin from honey bee venom, and its derivative tertiapin-Q directly block $\mathrm{I}_{\mathrm{KACh}}$ with nanomolar affinity by binding to the external end of the ion conduction pore (Jin and Lu, 1998). Tertiapin blocks $\mathrm{I}_{\mathrm{KACh}}$ current in a receptor- and voltage-independent manner without affecting other cardiac ionic currents (Drici et al., 2000). It has been demonstrated that tertiapin terminates AF without affecting ventricular repolarization in canine AF model (Hashimoto et al., 2006).

The benzopyran compound NIP-151 significantly inhibits $\mathrm{I}_{\mathrm{KACh}}$, and effectively terminates AF in canine model with an atrial-specific ERP-prolonging profile and lower risk of proarrhythmia compared with $\mathrm{I}_{\mathrm{Kr}}$ blockers (Hashimoto et al., 2008). AVE0118, in addition to inhibiting $\mathrm{I}_{\text {tol }}$ and $\mathrm{I}_{\mathrm{Kur}}$, blocks $\mathrm{I}_{\mathrm{KACh}}$ channels, and demonstrates atrial-specific antiarrhythmic effects in animal models (Blaauw et al., 2004; Gogelein et al., 2004). AVE1231, which has improved pharmacokinetic properties compared to AVE0118, shows similar effects on $\mathrm{I}_{\mathrm{KACh}}$ current (Wirth et al., 2007). The natural flavone accacetin also inhibits $\mathrm{I}_{\mathrm{KACh}}$ along with $\mathrm{I}_{\mathrm{Kur}}$ and $\mathrm{I}_{\text {tol }}$ and prevents AF in a canine model (Li et al., 2008) (Table 1).

In addition, the benzothiazepine compound JTV-519 (K201) inhibits $\mathrm{I}_{\mathrm{KACh}}$ and suppresses experimental $\mathrm{AF}$ in isolated guinea pig hearts (Nakaya et al., 2000). SD-3212 (levo-semotiadil fumarate), a novel benzothiazine $\mathrm{Ca}^{2+}$ channel antagonist, also inhibits $\mathrm{I}_{\mathrm{KACh}}$ channels by depressing the function of the channel itself and/or associated GTP-binding proteins (Hara and Nakaya, 1995) and shows anti-atrial arrhythmic effect (Fujiki et al., 1997).

Moreover, classical antiarrhythmic agents with a broad channel blockade profile, such as amiodarone 
and the structurally related derivatives, dronedarone (SR33589) and KB130015, also block cardiac $\mathrm{I}_{\mathrm{KACh}}$ with high potency by either disrupting G-protein-mediated activation or directly inhibiting interaction with the channel protein (Guillemare et al., 2000; Mubagwa et al., 2003). Blockade of $\mathrm{I}_{\mathrm{KACh}}$ by flaceinide contributes at least in part to the anti-AF effect in humans.

\section{Cardiac ATP-sensitive $\mathrm{K}^{+}$current, $\mathrm{I}_{\mathrm{KATP}}$}

Cardiac $\mathrm{I}_{\text {KATP }}$ is carried by ATP sensitive $\mathrm{K}^{+}$channels. $\mathrm{K}_{\text {ATP }}$ channels are closed at physiological intracellular ATP concentrations, and activated by a decrease in ratio of intracellular ATP/ADP (Noma, 1983). $\mathrm{K}_{\text {ATP }}$ channels act as a unique metabolic sensor or a coupling between the cell metabolic status and the cellular membrane potential. $\mathrm{I}_{\text {KATP }}$ plays a pivotal role in maintaining cardiac homeostasis under stress, such as myocardial ischemia/reperfusion and hypoxia, and mediate the ischemia-induced electrophysiological changes and cardioprotective effect of preconditioning (Zingman et al., 2007). Activation of $\mathrm{I}_{\text {KATP }}$ shortens cardiac APD by accelerating the phase 3 repolarization, reduces $\mathrm{Ca}^{2+}$ influx thereby preventing cardiac $\mathrm{Ca}^{2+}$ overload, preserves ATP levels (energy-sparing effects) and increases cell survival during myocardial ischemia (Tamargo et al., 2004; Tsuboi et al., 2004). On the other hand, activation of I IATP may also be 'cardiotoxic' by inducing re-entrant ventricular arrhythmias (Tamargo et al., 2004; Zunkler, 2006).

\section{A. Molecular identification of $\mathbf{I}_{\mathrm{KATP}}$}

$\mathrm{K}_{\text {ATP }}$ channels are composed of Kir 6.x-type subunits and sulfonylurea receptor (SUR) subunits (Fig. 2), along with additional components (Stephan et al., 2006). They are further identified by their location within the cell as being either sarcolemmal ( $\operatorname{sarcK}_{\mathrm{ATP}}$ ) or mitochondrial (mitoK $\mathrm{ATP}_{\mathrm{ATP}}$ (Foster et al., 2008; O'Rourke, 2004). Cardiac sarcK $\mathrm{K}_{\mathrm{ATP}}$ channels are a hetero-octameric complex composed of four inwardly-rectifying Kir6.2 channel pore subunits (encoded by KCNJ11), which confer inhibition by ATP, and four modulatory sulfonylurea receptor SUR2A (encoded by ABCC9) subunits (Billman, 2008; Tamargo et al., 2004).

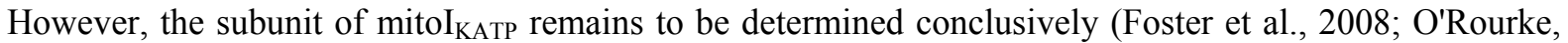
2004). A recent study demonstrated that the SUR2-IES is the $\beta$-subunit of mitoKATP channels (Ye et al., 2009). The SUR2A subunit (Fig. 2) has three hydrophobic transmembrane domains (TMD0, TMD1 and TMD2) that likely include five, six and six transmembrane segments respectively, with two hydrophilic nucleotide binding folds (NBF1 and NBF2) following TMD1 and TMD2 (Conti et al., 2001). SUR2A contains ATPase activity harbored within NBF2 and, to a lesser degree, NBF1. NBD1/NBD2 assembly provides a molecular substrate that determines the optimal catalytic activity in SUR2A (Park et al., 2008).

Defective mutations and polymorphisms in Kir6.2 are associated with increased risk of many kinds of metabolic disorders (Reyes et al., 2009). Disruption of sarcI $\mathrm{I}_{\text {KATP }}$ activity impairs cardiac adaptation to stress such as systolic overload (Reyes et al., 2009). Kir6.2 $2^{-}$mice present with an aberrant regulation of cardiomyocyte membrane excitability and $\mathrm{Ca}^{2+}$ handling, and are susceptible to ventricular arrhythmias and sudden death following sympathetic stimulation (Zingman et al., 2002).

\section{B. Signaling regulation of $\mathbf{I}_{\mathrm{KATP}}$}

In addition to regulation by the intracellular ATP and ADP (Noma, 1983), $\mathrm{I}_{\text {KATP }}$ is regulated by PKC, PTK, PIP2, nitric oxide, and many other signaling molecules. PKC activates cardiac $\mathrm{I}_{\mathrm{KATP}}$ channels at near physiological levels of ATP and induces ischemic preconditioning (Light et al., 1996). Isoform-dependent activation of PKC contributes to the persistent opening of $\mathrm{I}_{\mathrm{KATP}}$ channels during reoxygenation and reperfusion (Ito et al., 2001). Mitochondrial connexin 43 (Cx43) is recently found to regulate mitoK $_{\mathrm{ATP}}$ and protects cardiac cells from death. Genetic Cx43 deficiency, pharmacological $\mathrm{Cx} 43$ inhibition by carbenoxolone or by mimetic peptide substantially reduces diazoxide-mediated stimulation of mitoK $\mathrm{ATP}_{\mathrm{P}}$ channels. Suppression of mitochondrial $\mathrm{Cx} 43$ inhibits mitoK $\mathrm{ATP}_{\mathrm{T}}$ channel activation by PKC (Rottlaender et al., 2010). A recent review (Akrouh et al., 2009) is recommended for the detailed information of $\mathrm{K}_{\mathrm{ATP}}$ channel regulation.

\section{Pharmacology of $\mathbf{I}_{\mathrm{KATP}}$}

In addition to inhibition by intracellular ATP (Noma, 1983), $\mathrm{K}_{\mathrm{ATP}}$ channels can be blocked by antidiabetic drugs including the sulfonylureas, e.g. glibenclamide, glicazide, glipizide, glimepiride, tolbutamide and the glinides such as repaglinide, nateglinide, mitiglinide as well as some anti-arrhythmic drugs (e.g. flecainide) (Tamargo et al., 2004). Sulfonylurea drugs bind directly to the SUR region in the loop between TM15 and TM16 in TMD2 and S1237. These drugs have been widely used to regulate $\mathrm{K}_{\mathrm{ATP}}$ channel activity (Conti et al., 2001)

Because $\mathrm{K}_{\mathrm{ATP}}$ channels in pancreatic $\beta$-cells and smooth muscle regulate insulin secretion and vascular tone (Seino and Miki, 2003), I $\mathrm{I}_{\mathrm{KATP}}$ blockers may therefore induce hypoglycemia and coronary vasoconstriction; however, cardioselective $\mathrm{K}_{\mathrm{ATP}}$ channel blockers may be beneficial for treating cardiac 
disorders. The cardioselective $\mathrm{K}_{\mathrm{ATP}}$ channel blocker HMR 1098 (clamikalant) (Liu et al., 2001) reduces the cardiac APD shortening induced by hypoxia and prevents ventricular fibrillation induced by coronary artery occlusion in post-infarcted conscious dogs at doses that have no effect on insulin release, blood pressure or coronary blood flow (Grover and Garlid, 2000). Thus, specific cardiac I $\mathrm{I}_{\mathrm{KATP}}$ channel blockers may represent a new therapeutic approach to treat ischemia-induced ventricular arrhythmias with little or no side effects (Billman, 2008).

The $\mathrm{K}_{\mathrm{ATP}}$ channel activators, e.g. pinacidil, cromakalim, rimakalim and nicorandil, are found to open $\mathrm{K}_{\mathrm{ATP}}$ channels by binding to two distinct regions of TMD2, the intracellular loop joining TM13 and TM14 and between TM15 and TM16 (residues K1249 and T1253) (Moreau et al., 2000). These compounds have ischemia preconditioning effect and are cardioprotective in experimental myocardial ischemia/reperfusion models and in patients with acute myocardial infarction (Grover and Garlid, 2000). However, they also activate vascular $\mathrm{K}_{\mathrm{ATP}}$ channels (Kir6.1/SUR2B) and induce hypotension which limits their use in the treatment of myocardial ischemia.

It is believed that sarcK $\mathrm{K}_{\mathrm{ATP}}$ channels are responsible for ischemia preconditioning (Grover and Garlid, 2000). Indeed the mitoK $\mathrm{K}_{\mathrm{ATP}}$ channel activator diazoxide mimics the ischemic preconditioning, and the effect is countered by the selective mitoK $\mathrm{ATP}_{\mathrm{AT}}$ blocker 5-hydroxydecanoate $(5-\mathrm{HD})$. The selective mitoKATP opener BMS-191095 exerts cardioprotective effects without shortening APD or inducing hypotension effect

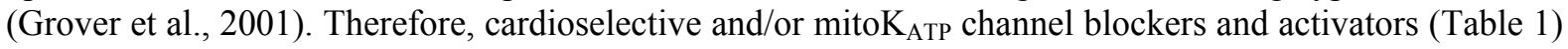
would be beneficial in protection of cardiac ischemia/reperfusion.

\section{Cardiac two pore $K^{+}$current $K_{2 P}$}

The two pore domain $\mathrm{K}^{+}\left(\mathrm{K}_{2 \mathrm{P}}\right)$ channels have been discovered for more than a decade, and they support background $\mathrm{K}^{+}$currents and maintain membrane potential in many cell types (see reviews, Gurney and Manoury, 2009; Judge and Smith, 2009). The distinct $\mathrm{K}_{2 \mathrm{P}}$ channels including four subfamilies of TASK, TWIK, TREK and THIK. $\mathrm{K}_{2 \mathrm{P}}$ channels comprise of four transmembrane domains and two pore-forming $\mathrm{P}$ loops arranged in tandem (Fig. 2) (Gurney and Manoury, 2009). $\mathrm{K}_{2 \mathrm{P}}$ channels are sensitive to membrane stretch, $\mathrm{pH}$ variation, phospholipids, fatty acids, volatile anaesthetics and G-protein coupled receptors (Bayliss and Barrett, 2008); however, they are insensitive to conventional $\mathrm{K}^{+}$channel blockers such as 4-AP, TEA, $\mathrm{Ba}^{2+}, \mathrm{Cs}^{+}$and glibenclamide (Gurney and Manoury, 2009; Tamargo et al., 2004).

In the heart, the resting membrane potential and cell excitability is predominantly contributed by $\mathrm{I}_{\mathrm{K} 1}$. Although the mRNAs of several $\mathrm{K}_{2 \mathrm{P}}$ channels (e.g. TREK-1 and TASK-1) are detected, the proposed contribution of these channels to cardiac background currents and cellular physiology are still unclear. No functional current has been recorded in human cardiomyocytes (Gurney and Manoury, 2009). However, because $\mathrm{K}_{2 \mathrm{P}}$ channels are sensitive to cellular or extracellular signals ( $\mathrm{pH}$ level, membrane stretch, etc), so they likely act as cellular sensor and transducers (O'Connell et al., 2002). Effort should be made in the future to find out pharmacological tools that select for these channels in order to further understand the physiological importance and whether these channels regulate cardiac functions (Gurney and Manoury, 2009; O'Connell et al., 2002; Tamargo et al., 2004).

\section{Conclusion}

The electrical properties of atria and ventricles of human heart are different in the distinct roles of cardiac physiology. Studies on cellular electrophysiology and ion channels have greatly improved our understanding of atrial and ventricular arrhythmias at cellular and molecular levels, including atrial fibrillation and life threatening ventricular arrhythmias. Cardiac $\mathrm{K}^{+}$channels have been recognized as potential therapeutic targets. The understanding of the ion channel distribution in the atria and ventricles and the pathophysiological alteration in different ion channels induced by genetics, diseases and/or medications has provided a basis for rational design of safer and more effective $\mathrm{K}^{+}$channel blockers and/or activators to prevent/treat atrial fibrillation and/or ventricular arrhythmias.

The improved understanding of molecular basis for cardiac $\mathrm{I}_{\mathrm{Kr}}$ and $\mathrm{I}_{\mathrm{Ks}}$ makes it possible for the pharmaceuticals to develop selective $\mathrm{I}_{\mathrm{Kr}} / \mathrm{hERG}$ channel activators (e.g. PR260243, PD-118057, etc.) and/or $\mathrm{I}_{\mathrm{Ks}}$ activators (e.g. RL-3, tanshinone, etc), which may offer a new approach in the treatment of delayed repolarization conditions in patients with acquired long QT syndrome or inherited long QT syndrome, congestive heart failure, and diabetes. In the last decade, effort has been made to develop new anti-arrhythmic agents with safer and more effective than those presently used, especially 'atrial-selective drugs' that target cardiac ion channel(s) that are exclusively or predominantly expressed in the atria to avoid the proarrhythmic effect of class III antiarrhthmic drugs. $\mathrm{I}_{\mathrm{Kur}}$ is a major repolarizing current in human atria, but not in the ventricles, so that blocking of $\mathrm{I}_{\mathrm{Kur}}$ is thought to be a promising target for atrial-specific therapy of AF. $\mathrm{I}_{\mathrm{KACh}}$ channels are predominantly present in atria, but largely sparse in ventricles of the heart. 
Compounds that selectively inhibit $\mathrm{I}_{\mathrm{Kur}}\left(\mathrm{e} . \mathrm{g} . \mathrm{DPO}-1\right.$, ISQ-1, etc.) or $\mathrm{I}_{\mathrm{KACh}}(\mathrm{e} . \mathrm{g}$. tertiapin, tertiapin-Q, etc.) or both $\mathrm{I}_{\mathrm{Kur}}$ and $\mathrm{I}_{\mathrm{KACh}}$ (e.g. AVE0118, AVE1231, acacetin, etc.) have been demonstrated to terminate or prevent experimental AF. Therefore, these compounds are thought to be a promising target for atrial-specific therapy of AF. Because $\mathrm{I}_{\mathrm{tol}}$ channels are more significant for atrial repolarization than that in ventricles, the compounds with $\mathrm{I}_{\text {tol }}$ block (e.g. vernakalant, AVE0118, acacetin, etc.) would be a plus for anti-AF. These atrial-selective compounds should be further studied to demonstrate whether they are the desired drugs that are not only effective in clinically relevant AF animal models, but also satisfied in oral bioavailability and safe in animals following repeat dosing; and, crucially, clinical efficacy and safety. The studies on cardiac selective $\mathrm{K}_{\text {ATP }}$ channel inhibitor (e.g. clamikalant) or mitoK $_{\text {ATP }}$ activators (e.g. atpenin A5, P1705) (Table 1) are being progressed for the protection of cardiac ischemia/reperfusion. The remained question is whether $\mathrm{I}_{\mathrm{K} 1}$ is a target for developing specific activators to treat certain type of arrhythmias related to delayed reploarization.

\section{Acknowledgement}

This work was supported in part by a General Research Fund (HKU 760306M) from Research Grant Council of Hong Kong.

Conflict of Interest statement: The authors have no conflicts of interest to declare. 


\section{References}

Akrouh, A., Halcomb, S. E., Nichols, C. G., et al. (2009). Molecular biology of K(ATP) channels and implications for health and disease. IUBMB Life. 61, 971-978.

Anumonwo, J. M., Lopatin, A. N. (2010). Cardiac strong inward rectifier potassium channels. J Mol Cell Cardiol. 48, 45-54.

Arora, R., Ng, J., Ulphani, J., et al. (2007). Unique autonomic profile of the pulmonary veins and posterior left atrium. J Am Coll Cardiol. 49, 1340-1348.

Atienza, F., Almendral, J., Moreno, J., et al. (2006). Activation of inward rectifier potassium channels accelerates atrial fibrillation in humans: evidence for a reentrant mechanism. Circulation, 114, 2434-2442.

Bai, C. X., Takahashi, K., Masumiya, H., et al. (2004). Nitric oxide-dependent modulation of the delayed rectifier $\mathrm{K}^{+}$current and the L-type $\mathrm{Ca}^{2+}$ current by ginsenoside $\mathrm{Re}$, an ingredient of Panax ginseng, in guinea-pig cardiomyocytes. Br J Pharmacol. 142, 567-575.

Barhanin, J., Lesage, F., Guillemare, E., et al. (1996). K(V)LQT1 and lsK (minK) proteins associate to form the I(Ks) cardiac potassium current. Nature. 384, 78-80.

Bayliss, D. A., Barrett, P. Q. (2008). Emerging roles for two-pore-domain potassium channels and their potential therapeutic impact. Trends Pharmacol Sci. 29, 566-575.

Bett, G. C., Rasmusson, R. L. (2008). Modification of $\mathrm{K}^{+}$channel-drug interactions by ancillary subunits. $J$ Physiol. 586, 929-950.

Bian, J. S., Kagan, A., \& McDonald, T. V. (2004). Molecular analysis of PIP2 regulation of HERG and $\mathrm{I}_{\mathrm{Kr}}$. Am J Physiol Heart Circ Physiol. 287, H2154-2163.

Biliczki, P., Virag, L., Iost, N., et al. (2002). Interaction of different potassium channels in cardiac repolarization in dog ventricular preparations: role of repolarization reserve. Br J Pharmacol. 137, 361-368.

Billman, G. E. (2008). The cardiac sarcolemmal ATP-sensitive potassium channel as a novel target for anti-arrhythmic therapy. Pharmacol Ther. 120, 54-70.

Blaauw, Y., Gogelein, H., Tieleman, R. G., et al. (2004). "Early" class III drugs for the treatment of atrial fibrillation: efficacy and atrial selectivity of AVE0118 in remodeled atria of the goat. Circulation. 110, 1717-1724.

Borlak, J., Thum, T. (2003). Hallmarks of ion channel gene expression in end-stage heart failure. FASEB J. $17,1592-1608$.

Bosche, L. I., Wellner-Kienitz, M. C., Bender, K., et al. (2003). G protein-independent inhibition of GIRK current by adenosine in rat atrial myocytes overexpressing A1 receptors after adenovirus-mediated gene transfer. J Physiol. 550, 707-717.

Boyle, W. A., Nerbonne, J. M. (1992). Two functionally distinct 4-aminopyridine-sensitive outward $\mathrm{K}^{+}$ currents in rat atrial myocytes. J Gen Physiol. 100, 1041-1067.

Brandts, B., Borchard, R., Macianskiene, R., et al. (2004). Inhibition of G protein-coupled and ATP-sensitive potassium currents by 2-methyl-3-(3,5-diiodo-4-carboxymethoxybenzyl)benzofuran (KB130015), an amiodarone derivative. J Pharmacol Exp Ther. 308, 134-142.

Brandts, B., Van Bracht, M., Tuttelmann, F., et al. (2000). Inhibition of muscarinic potassium current by the class III antiarrhythmic drug RP58866 in guinea-pig atrial myocytes. Pacing Clin Electrophysio., 23, 1812-1815.

Brugada, R., Hong, K., Dumaine, R., et al. (2004). Sudden death associated with short-QT syndrome linked to mutations in HERG. Circulation. 109, 30-35.

Brundel, B. J., Van Gelder, I. C., Henning, R. H., et al. (2001). Alterations in potassium channel gene expression in atria of patients with persistent and paroxysmal atrial fibrillation: differential regulation of protein and mRNA levels for K+ channels. J Am Coll Cardiol. 37, 926-932.

Busch, A. E., Suessbrich, H., Waldegger, S., et al. (1996). Inhibition of $\mathrm{I}_{\mathrm{Ks}}$ in guinea pig cardiac myocytes and guinea pig IsK channels by the chromanol 293B. Pflugers Arch. 432, 1094-1096.

Caballero, R., Moreno, I., Gonzalez, T., et al. (2003). Spironolactone and its main metabolite, canrenoic acid, block human ether-a-go-go-related gene channels. Circulation. 107, 889-895.

Caballero, R., Moreno, I., Gonzalez, T., et al. (2002). Putative binding sites for benzocaine on a human cardiac cloned channel (Kv1.5). Cardiovasc Res. 56, 104-117.

Calloe, K., Ravn, L. S., Schmitt, N., et al. (2007). Characterizations of a loss-of-function mutation in the Kir3.4 channel subunit. Biochem Biophys Res Commun. 364, 889-895.

Charpentier, F., Merot, J., Loussouarn, G., et al. (2010). Delayed rectifier K(+) currents and cardiac repolarization. J Mol Cell Cardiol. 48, 37-44.

Cheng, H. C., Incardona, J. (2009). Models of torsades de pointes: effects of FPL64176, DPI201106, 
dofetilide, and chromanol 293B in isolated rabbit and guinea pig hearts. J Pharmacol Toxicol Methods. 60, 174-184.

Christ, T., Wettwer, E., Voigt, N., et al. (2008). Pathology-specific effects of the $\mathrm{I}_{\mathrm{Kur}} / \mathrm{I}_{\mathrm{t}} / \mathrm{I}_{\mathrm{K}, \mathrm{ACh}}$ blocker AVE0118 on ion channels in human chronic atrial fibrillation. Br J Pharmacol. 154, 1619-1630.

Conti, L. R., Radeke, C. M., Shyng, S. L., et al. (2001). Transmembrane topology of the sulfonylurea receptor SUR1. J Biol Chem. 276, 41270-41278.

Corey, S., Krapivinsky, G., Krapivinsky, L., et al. (1998). Number and stoichiometry of subunits in the native atrial G-protein-gated $\mathrm{K}^{+}$channel, $\mathrm{I}_{\mathrm{KACh}}$. J Biol Chem. 273, 5271-5278.

Crumb, W. J., Jr. (1999). Rate-dependent blockade of a potassium current in human atrium by the antihistamine loratadine. Br J Pharmacol. 126, 575-580.

Crumb, W. J., Jr. (2000). Loratadine blockade of K(+) channels in human heart: comparison with terfenadine under physiological conditions. J Pharmacol Exp Ther. 292, 261-264.

Davis-Taber, R., Molinari, E. J., Altenbach, R. J., et al. (2003). [125I]A-312110, a novel high-affinity 1,4-dihydropyridine ATP-sensitive $\mathrm{K}+$ channel opener: characterization and pharmacology of binding. Mol Pharmacol. 64, 143-153.

de Haan, S., Greiser, M., Harks, E., et al. (2006). AVE0118, blocker of the transient outward current (I(to)) and ultrarapid delayed rectifier current ( $($ (Kur)), fully restores atrial contractility after cardioversion of atrial fibrillation in the goat. Circulation. 114, 1234-1242.

Decher, N., Gonzalez, T., Streit, A. K., et al. (2008). Structural determinants of Kvbeta1.3-induced channel inactivation: a hairpin modulated by PIP2. EMBO J. 27, 3164-3174.

Decher, N., Kumar, P., Gonzalez, T., et al. (2006). Binding site of a novel Kv1.5 blocker: a "foot in the door" against atrial fibrillation. Mol Pharmacol. 70, 1204-1211.

Decher, N., Pirard, B., Bundis, F., et al. (2004). Molecular basis for Kv1.5 channel block: conservation of drug binding sites among voltage-gated $\mathrm{K}^{+}$channels. J Biol Chem. 279, 394-400.

Dennis, A., Wang, L., Wan, X., et al. (2007). hERG channel trafficking: novel targets in drug-induced long QT syndrome. Biochem Soc Trans. 35, 1060-1063.

Dhamoon, A. S., Pandit, S. V., Sarmast, F., et al. (2004). Unique Kir2.x properties determine regional and species differences in the cardiac inward rectifier $\mathrm{K}^{+}$current. Circ Res. 94, 1332-1339.

Dixon, J. E., Shi, W., Wang, H. S., et al. (1996). Role of the Kv4.3 K ${ }^{+}$channel in ventricular muscle. A molecular correlate for the transient outward current. Circ Res. 79, 659-668.

Dobrev, D., Friedrich, A., Voigt, N., et al. (2005). The G protein-gated potassium current I(K,ACh) is constitutively active in patients with chronic atrial fibrillation. Circulation. 112, 3697-3706.

Dobrev, D., Nattel, S. (2010). New antiarrhythmic drugs for treatment of atrial fibrillation. Lancet. 375, 1212-1223.

Dobrev, D., Wettwer, E., Kortner, A., et al. (2002). Human inward rectifier potassium channels in chronic and postoperative atrial fibrillation. Cardiovasc Res. 54, 397-404.

Dobrzynski, H., Marples, D. D., Musa, H., et al. (2001). Distribution of the muscarinic $\mathrm{K}^{+}$channel proteins Kir3.1 and Kir3.4 in the ventricle, atrium, and sinoatrial node of heart. J Histochem Cytochem. 49, 1221-1234.

Dong, M.Q., Sun, H.Y., Tang, Q., et al. (2010). Regulation of human cardiac KCNQ1/KCNE1 channel by epidermal growth factor receptor kinase. Biochim Biophys Acta. 1798, 995-1001.

Doolan, G. K., Panchal, R. G., Fonnes, E. L., et al. (2002). Fatty acid augmentation of the cardiac slowly activating delayed rectifier current (IKs) is conferred by hminK. FASEB J. 16, 1662-1664.

Doronin, S. V., Potapova, I. A., Lu, Z., et al. (2004). Angiotensin receptor type 1 forms a complex with the transient outward potassium channel $\mathrm{Kv} 4.3$ and regulates its gating properties and intracellular localization. J Biol Chem. 279, 48231-48237.

Drici, M. D., Diochot, S., Terrenoire, C., et al. (2000). The bee venom peptide tertiapin underlines the role of I(KACh) in acetylcholine-induced atrioventricular blocks. Br J Pharmacol. 131, 569-577.

Du, Y. M., Zhang, X. X., Tu, D. N., et al. (2010). Molecular determinants of Kv1.5 channel block by diphenyl phosphine oxide-1. J Mol Cell Cardiol. 48, 1111-1120

Ehrlich, J. R. (2008). Inward rectifier potassium currents as a target for atrial fibrillation therapy. $J$ Cardiovasc Pharmacol. 52, 129-135.

Ehrlich, J. R., Ocholla, H., Ziemek, D., et al. (2008). Characterization of human cardiac Kv1.5 inhibition by the novel atrial-selective antiarrhythmic compound AVE1231. J Cardiovasc Pharmacol. 51, 380-387.

El-Haou, S., Balse, E., Neyroud, N., et al. (2009). Kv4 potassium channels form a tripartite complex with the anchoring protein SAP97 and CaMKII in cardiac myocytes. Circ Res. 104, 758-769.

Eldstrom, J., Wang, Z., Xu, H., et al. (2007). The molecular basis of high-affinity binding of the antiarrhythmic compound vernakalant (RSD1235) to Kv1.5 channels. Mol Pharmacol. 72, 1522-1534.

Farkas, A. S., Nattel, S. (2010). Minimizing repolarization-related proarrhythmic risk in drug development 
and clinical practice. Drugs. 70, 573-603.

Fedida, D. (2007). Vernakalant (RSD1235): a novel, atrial-selective antifibrillatory agent. Expert Opin Investig Drugs. 16, 519-532.

Fedida, D., Eldstrom, J., Hesketh, J. C., et al. (2003). Kv1.5 is an important component of repolarizing K+ current in canine atrial myocytes. Circ Res. 93, 744-751.

Fedida, D., Orth, P. M., Chen, J. Y., et al. (2005). The mechanism of atrial antiarrhythmic action of RSD1235. J Cardiovasc Electrophysiol. 16, 1227-1238.

Fedida, D., Shimoni, Y., \& Giles, W. R. (1990). Alpha-adrenergic modulation of the transient outward current in rabbit atrial myocytes. J Physiol. 423, 257-277.

Fedida, D., Wible, B., Wang, Z., et al. (1993). Identity of a novel delayed rectifier current from human heart with a cloned $\mathrm{K}^{+}$channel current. Circ Res. 73, 210-216.

Feng, J., Wang, Z., Li, G. R., et al. (1997). Effects of class III antiarrhythmic drugs on transient outward and ultra-rapid delayed rectifier currents in human atrial myocytes. J Pharmacol Exp Ther. 281, 384-392.

Feng, J., Wible, B., Li, G. R., et al. (1997). Antisense oligodeoxynucleotides directed against Kv1.5 mRNA specifically inhibit ultrarapid delayed rectifier $\mathrm{K}+$ current in cultured adult human atrial myocytes. Circ Res. 80, 572-579.

Ficker, E., Jarolimek, W., Kiehn, J., et al. (1998). Molecular determinants of dofetilide block of HERG K+ channels. Circ Res. 82, 386-395.

Ford, J. W., Milnes, J. T. (2008). New drugs targeting the cardiac ultra-rapid delayed-rectifier current (I Kur): rationale, pharmacology and evidence for potential therapeutic value. J Cardiovasc Pharmacol. $52,105-120$.

Foster, D. B., Rucker, J. J., \& Marban, E. (2008). Is Kir6.1 a subunit of mitoK(ATP)? Biochem Biophys Res Commun. 366, 649-656.

Franqueza, L., Longobardo, M., Vicente, J., et al. (1997). Molecular determinants of stereoselective bupivacaine block of hKv1.5 channels. Circ Res. 81, 1053-1064.

Fujiki, A., Tani, M., Hayashi, H., et al. (1997). Electrophysiologic effects of SD-3212, a new class I antiarrhythmic drug, on canine atrial flutter and atrial action-potential characteristics. $J$ Cardiovasc Pharmacol. 29, 471-475.

Gaborit, N., Le Bouter, S., Szuts, V., et al. (2007). Regional and tissue specific transcript signatures of ion channel genes in the non-diseased human heart. J Physiol. 582, 675-693.

Gao, Z., Lau, C. P., Chiu, S. W., et al. (2004). Inhibition of ultra-rapid delayed rectifier K+ current by verapamil in human atrial myocytes. J Mol Cell Cardiol. 36, 257-263.

Gao, Z., Sun, H., Chiu, S. W., et al. (2005). Effects of diltiazem and nifedipine on transient outward and ultra-rapid delayed rectifier potassium currents in human atrial myocytes. Br J Pharmacol. 144, 595-604.

Gerlach, A. C., Stoehr, S. J., \& Castle, N. A. (2010). Pharmacological removal of human ether-a-go-go-related gene potassium channel inactivation by 3-nitro-N-(4-phenoxyphenyl) benzamide (ICA-105574). Mol Pharmacol. 77, 58-68.

Gessner, G., Macianskiene, R., Starkus, J. G., et al. (2010). The amiodarone derivative KB130015 activates hERG1 potassium channels via a novel mechanism. Eur J Pharmacol. 632, 52-59.

Girmatsion, Z., Biliczki, P., Bonauer, A., et al. (2009). Changes in microRNA-1 expression and IK1 up-regulation in human atrial fibrillation. Heart Rhythm. 6, 1802-1809.

Gogelein, H., Brendel, J., Steinmeyer, K., et al. (2004). Effects of the atrial antiarrhythmic drug AVE0118 on cardiac ion channels. Naunyn Schmiedebergs Arch Pharmacol. 370, 183-192.

Gomes, P., Saito, T., Del Corsso, C., et al. (2008). Identification of a functional interaction between Kv4.3 channels and c-Src tyrosine kinase. Biochim Biophys Acta. 1783, 1884-1892.

Gomez, R., Caballero, R., Barana, A., et al. (2009). Nitric oxide increases cardiac $\mathrm{I}_{\mathrm{K} 1}$ by nitrosylation of cysteine 76 of Kir2.1 channels. Circ Res. 105, 383-392.

Gomez, R., Nunez, L., Caballero, R., et al. (2005). Spironolactone and its main metabolite canrenoic acid block hKv1.5, Kv4.3 and Kv7.1 + minK channels. Br J Pharmacol. 146, 146-161.

Gomez, R., Nunez, L., Vaquero, M., et al. (2008). Nitric oxide inhibits Kv4.3 and human cardiac transient outward potassium current $\left(\mathrm{I}_{\mathrm{to} 1}\right)$. Cardiovasc Res. 80, 375-384.

Gong, Y. Z., Ding, W. G., Wu, J., et al. (2008). Cinnamyl-3,4-dihydroxy-alpha-cyanocinnamate and nordihydroguaiaretic acid inhibit human Kv1.5 currents independently of lipoxygenase. Eur $J$ Pharmacol. 600, 18-25.

Gordon, E., Lozinskaya, I. M., Lin, Z., et al. (2008). 2-[2-(3,4-dichloro-phenyl)-2,3-dihydro-1Hisoindol-5-ylamino]-nicotinic acid (PD-307243) causes instantaneous current through human ether-a-go-go-related gene potassium channels. Mol Pharmacol. 73, 639-651.

Gordon, E., Panaghie, G., Deng, L., et al. (2008). A KCNE2 mutation in a patient with cardiac arrhythmia 
induced by auditory stimuli and serum electrolyte imbalance. Cardiovasc Res. 77, 98-106.

Grammer, J. B., Bosch, R. F., Kuhlkamp, V., et al. (2000). Molecular remodeling of Kv4.3 potassium channels in human atrial fibrillation. $J$ Cardiovasc Electrophysiol. 11, 626-633.

Grover, G. J., D'Alonzo, A. J., Garlid, K. D., et al. (2001). Pharmacologic characterization of BMS-191095, a mitochondrial K(ATP) opener with no peripheral vasodilator or cardiac action potential shortening activity. J Pharmacol Exp Ther. 297, 1184-1192.

Grover, G. J., Garlid, K. D. (2000). ATP-Sensitive potassium channels: a review of their cardioprotective pharmacology. J Mol Cell Cardiol. 32, 677-695.

Guillemare, E., Marion, A., Nisato, D., et al. (2000). Inhibitory effects of dronedarone on muscarinic K+ current in guinea pig atrial cells. J Cardiovasc Pharmacol. 36, 802-805.

Guo, J., Massaeli, H., Xu, J., et al. (2009). Extracellular $\mathrm{K}^{+}$concentration controls cell surface density of $\mathrm{I}_{\mathrm{Kr}}$ in rabbit hearts and of the HERG channel in human cell lines. J Clin Invest. 119, 2745-2757.

Gurney, A., Manoury, B. (2009). Two-pore potassium channels in the cardiovascular system. Eur Biophys J. 38, 305-318.

Hansen, R. S., Diness, T. G., Christ, T., et al. (2006). Activation of human ether-a-go-go-related gene potassium channels by the diphenylurea 1,3-bis-(2-hydroxy-5-trifluoromethyl-phenyl)-urea (NS1643). Mol Pharmacol. 69, 266-277.

Hansen, R. S., Diness, T. G., Christ, T., et al. (2006). Biophysical characterization of the new human ether-a-go-go-related gene channel opener NS3623 [N-(4-bromo-2-(1H-tetrazol-5-yl)-phenyl)-N'(3'-trifluoromethylphenyl)urea ]. Mol Pharmacol. 70, 1319-1329.

Hara, Y., Nakaya, H. (1995). SD-3212, a new class I and IV antiarrhythmic drug: a potent inhibitor of the muscarinic acetylcholine-receptor-operated potassium current in guinea-pig atrial cells. Br J Pharmacol. $116,2750-2756$.

Hashimoto, N., Yamashita, T., \& Tsuruzoe, N. (2006). Tertiapin, a selective $\mathrm{I}_{\mathrm{KACh}}$ blocker, terminates atrial fibrillation with selective atrial effective refractory period prolongation. Pharmacol Res. 54, 136-141.

Hashimoto, N., Yamashita, T., \& Tsuruzoe, N. (2008). Characterization of in vivo and in vitro electrophysiological and antiarrhythmic effects of a novel $\mathrm{I}_{\mathrm{KACh}}$ blocker, NIP-151: a comparison with an $\mathrm{I}_{\mathrm{Kr}}$-blocker dofetilide. J Cardiovasc Pharmacol. 51, 162-169.

Honore, E., Barhanin, J., Attali, B., et al. (1994). External blockade of the major cardiac delayed-rectifier K ${ }^{+}$ channel (Kv1.5) by polyunsaturated fatty acids. Proc Natl Acad Sci U S A. 91, 1937-1941.

Ito, K., Sato, T., \& Arita, M. (2001). Protein kinase C isoform-dependent modulation of ATP-sensitive $\mathrm{K}^{+}$ channels during reoxygenation in guinea-pig ventricular myocytes. J Physiol. 532, 165-174.

Jiang, M., Cabo, C., Yao, J., et al. (2000). Delayed rectifier K currents have reduced amplitudes and altered kinetics in myocytes from infarcted canine ventricle. Cardiovasc Res. 48, 34-43.

Jin, W., Lu, Z. (1998). A novel high-affinity inhibitor for inward-rectifier $\mathrm{K}^{+}$channels. Biochemistry. 37 , 13291-13299.

Jing, H., Luo, L., Li, H., et al. (2009). Ephedrine controls heart rhythms by activating cardiac $\mathrm{I}_{\mathrm{Ks}}$ currents. $J$ Cardiovasc Pharmacol. 55, 145-152.

Jost, N., Virag, L., Bitay, M., et al. (2005). Restricting excessive cardiac action potential and QT prolongation: a vital role for $\mathrm{I}_{\mathrm{Ks}}$ in human ventricular muscle. Circulation. 112, 1392-1399.

Judge, S. I., Smith, P. J. (2009). Patents related to therapeutic activation of K(ATP) and K(2P) potassium channels for neuroprotection: ischemic/hypoxic/anoxic injury and general anesthetics. Expert Opin Ther Pat. 19, 433-460.

Kaab, S., Dixon, J., Duc, J., et al. (1998). Molecular basis of transient outward potassium current downregulation in human heart failure: a decrease in Kv4.3 mRNA correlates with a reduction in current density. Circulation. 98, 1383-1393.

Kang, J., Chen, X. L., Wang, H., et al. (2005). Discovery of a small molecule activator of the human ether-a-go-go-related gene (HERG) cardiac $\mathrm{K}^{+}$channel. Mol Pharmacol. 67, 827-836.

Kannankeril, P. J., Roden, D. M. (2007). Drug-induced long QT and torsade de pointes: recent advances. Curr Opin Cardiol. 22, 39-43.

Karle, C. A., Zitron, E., Zhang, W., et al. (2002). Human cardiac inwardly-rectifying K+ channel Kir(2.1b) is inhibited by direct protein kinase $\mathrm{C}$-dependent regulation in human isolated cardiomyocytes and in an expression system. Circulation. 106, 1493-1499.

Kenyon, J. L., Gibbons, W. R. (1979). 4-Aminopyridine and the early outward current of sheep cardiac Purkinje fibers. J Gen Physiol. 73, 139-157.

Keselman, I., Fribourg, M., Felsenfeld, D. P., et al. (2007). Mechanism of PLC-mediated Kir3 current inhibition. Channels (Austin). 1, 113-123.

Kleber, A. G. (1994). IK1 blockade as an antiarrhythmic mechanism. Cardiovasc Res. 28, 720.

Klose, A., Huth, T., \& Alzheimer, C. (2008). 1-[6-[[(17beta)-3-methoxyestra-1,3,5(10)- 
trien-17-yl]amino]hexyl]-1H-pyrro le-2,5-dione (U73122) selectively inhibits Kir3 and BK channels in a phospholipase C-independent fashion. Mol Pharmacol. 74, 1203-1214.

Koumi, S., Backer, C. L., \& Arentzen, C. E. (1995). Characterization of inwardly rectifying K+ channel in human cardiac myocytes. Alterations in channel behavior in myocytes isolated from patients with idiopathic dilated cardiomyopathy. Circulation. 92, 164-174.

Koumi, S., Wasserstrom, J. A., \& Ten Eick, R. E. (1995). Beta-adrenergic and cholinergic modulation of inward rectifier $\mathrm{K}+$ channel function and phosphorylation in guinea-pig ventricle. $J$ Physiol. 486, 661-678.

Kozlowski, D., Budrejko, S., Lip, G. Y., et al. (2009). Vernakalant hydrochloride for the treatment of atrial fibrillation. Expert Opin Investig Drugs. 18, 1929-1937.

Kuryshev, Y. A., Ficker, E., Wang, L., et al. (2005). Pentamidine-induced long QT syndrome and block of hERG trafficking. J Pharmacol Exp Ther. 312, 316-323.

Kwak, Y. G., Hu, N., Wei, J., et al. (1999). Protein kinase A phosphorylation alters Kvbeta1.3 subunit-mediated inactivation of the Kv1.5 potassium channel. J Biol Chem. 274, 13928-13932.

Lagrutta, A., Wang, J., Fermini, B., et al. (2006). Novel, potent inhibitors of human Kv1.5 K+ channels and ultrarapidly activating delayed rectifier potassium current. J Pharmacol Exp Ther. 317, 1054-1063.

Lee, H. M., Hahn, S. J., \& Choi, B. H. (2010). Open channel block of Kv1.5 currents by citalopram. Acta Pharmacol Sin. 31, 429-435

Lengyel, C., Iost, N., Virag, L., et al. (2001). Pharmacological block of the slow component of the outward delayed rectifier current (I(Ks)) fails to lengthen rabbit ventricular muscle QT(c) and action potential duration. Br J Pharmacol. 132, 101-110.

Levitan, I. (2009). Cholesterol and Kir channels. IUBMB Life. 61, 781-790.

Li, G. R., Feng, J., Wang, Z., et al. (1995). Comparative mechanisms of 4-aminopyridine-resistant Ito in human and rabbit atrial myocytes. Am J Physiol. 269, H463-472.

Li, G. R., Feng, J., Wang, Z., et al. (1996). Adrenergic modulation of ultrarapid delayed rectifier K+ current in human atrial myocytes. Circ Res. 78, 903-915.

Li, G. R., Feng, J., Yue, L., et al. (1998). Transmural heterogeneity of action potentials and Ito1 in myocytes isolated from the human right ventricle. Am J Physiol. 275, H369-377.

Li, G. R., Feng, J., Yue, L., et al. (1996). Evidence for two components of delayed rectifier K+ current in human ventricular myocytes. Circ Res. 78, 689-696.

Li, G. R., Lau, C. P., Ducharme, A., et al. (2002). Transmural action potential and ionic current remodeling in ventricles of failing canine hearts. Am J Physiol Heart Circ Physiol. 283, H1031-1041.

Li, G. R., Lau, C. P., Leung, T. K., et al. (2004). Ionic current abnormalities associated with prolonged action potentials in cardiomyocytes from diseased human right ventricles. Heart Rhythm. 1, 460-468.

Li, G. R., Sun, H., \& Nattel, S. (1998). Characterization of a transient outward $\mathrm{K}^{+}$current with inward rectification in canine ventricular myocytes. Am J Physiol. 274, C577-585.

Li, G. R., Sun, H., To, J., et al. (2004). Demonstration of calcium-activated transient outward chloride current and delayed rectifier potassium currents in Swine atrial myocytes. J Mol Cell Cardiol. 36, 495-504.

Li, G. R., Sun, H. Y., Zhang, X. H., et al. (2009). Omega-3 polyunsaturated fatty acids inhibit transient outward and ultra-rapid delayed rectifier $\mathrm{K}^{+}$currents and $\mathrm{Na}^{+}$current in human atrial myocytes. Cardiovasc Res. 81, 286-293.

Li, G. R., Wang, H. B., Qin, G. W., et al. (2008). Acacetin, a natural flavone, selectively inhibits human atrial repolarization potassium currents and prevents atrial fibrillation in dogs. Circulation. 117, 2449-2457.

Light, P. E., Sabir, A. A., Allen, B. G., et al. (1996). Protein kinase C-induced changes in the stoichiometry of ATP binding activate cardiac ATP-sensitive $\mathrm{K}^{+}$channels. A possible mechanistic link to ischemic preconditioning. Circ Res. 79, 399-406.

Lin, S., Wang, Z., \& Fedida, D. (2001). Influence of permeating ions on Kv1.5 channel block by nifedipine. Am J Physiol Heart Circ Physiol. 280, H1160-1172.

Liu, D. W., Antzelevitch, C. (1995). Characteristics of the delayed rectifier current ( $\mathrm{I}_{\mathrm{Kr}}$ and $\left.\mathrm{I}_{\mathrm{Ks}}\right)$ in canine ventricular epicardial, midmyocardial, and endocardial myocytes. A weaker $\mathrm{I}_{\mathrm{Ks}}$ contributes to the longer action potential of the M cell. Circ Res. 76, 351-365.

Liu, D. W., Gintant, G. A., \& Antzelevitch, C. (1993). Ionic bases for electrophysiological distinctions among epicardial, midmyocardial, and endocardial myocytes from the free wall of the canine left ventricle. Circ Res. 72, 671-687.

Liu, H., Jin, M. W., Xiang, J. Z., et al. (2007). Raloxifene inhibits transient outward and ultra-rapid delayed rectifier potassium currents in human atrial myocytes. Eur J Pharmacol. 563, 61-68.

Liu, Y., Ren, G., O'Rourke, B., et al. (2001). Pharmacological comparison of native mitochondrial K(ATP) channels with molecularly defined surface K(ATP) channels. Mol Pharmacol. 59, 225-230. 
Lo, C. F., Numann, R. (1998). Independent and exclusive modulation of cardiac delayed rectifying $\mathrm{K}^{+}$ current by protein kinase C and protein kinase A. Circ Res. 83, 995-1002.

Lopatin, A. N., Makhina, E. N., \& Nichols, C. G. (1994). Potassium channel block by cytoplasmic polyamines as the mechanism of intrinsic rectification. Nature. 372, 366-369.

Lundby, A., Ravn, L. S., Svendsen, J. H., et al. (2007). KCNQ1 mutation Q147R is associated with atrial fibrillation and prolonged QT interval. Heart Rhythm. 4, 1532-1541.

MacKinnon, R. (1995). Pore loops: an emerging theme in ion channel structure. Neuron. 14, 889-892.

Martens, J. R., Kwak, Y. G., \& Tamkun, M. M. (1999). Modulation of Kv channel alpha/beta subunit interactions. Trends Cardiovasc Med. 9, 253-258.

McPate, M. J., Duncan, R. S., Witchel, H. J., et al. (2006). Disopyramide is an effective inhibitor of mutant HERG K ${ }^{+}$channels involved in variant 1 short QT syndrome. J Mol Cell Cardiol. 41, 563-566.

McPate, M. J., Zhang, H., Adeniran, I., et al. (2009). Comparative effects of the short QT N588K mutation at $37{ }^{\circ} \mathrm{C}$ on hERG $\mathrm{K}^{+}$channel current during ventricular, Purkinje fibre and atrial action potentials: an action potential clamp study. $J$ Physiol Pharmacol. 60, 23-41.

Mitcheson, J., Perry, M., Stansfeld, P., et al. (2005). Structural determinants for high-affinity block of hERG potassium channels. Novartis Found Symp. 266, 136-150; discussion 150-138.

Mitcheson, J. S. (2008). hERG potassium channels and the structural basis of drug-induced arrhythmias. Chem Res Toxicol. 21, 1005-1010.

Moreau, C., Jacquet, H., Prost, A. L., et al. (2000). The molecular basis of the specificity of action of K(ATP) channel openers. EMBO J. 19, 6644-6651.

Mruk, K., Kobertz, W. R. (2009). Discovery of a novel activator of KCNQ1-KCNE1 K channel complexes. PLoS One. 4, e4236.

Mubagwa, K., Macianskiene, R., Viappiani, S., et al. (2003). KB130015, a new amiodarone derivative with multiple effects on cardiac ion channels. Cardiovasc Drug Rev. 21, 216-235.

Mullner, C., Steinecker, B., Gorischek, A., et al. (2009). Identification of the structural determinant responsible for the phosphorylation of G-protein activated potassium channel 1 by cAMP-dependent protein kinase. FEBS J. 276, 6218-6226.

Nabauer, M., Beuckelmann, D. J., Uberfuhr, P., et al. (1996). Regional differences in current density and rate-dependent properties of the transient outward current in subepicardial and subendocardial myocytes of human left ventricle. Circulation. 93, 168-177.

Nakamura, T. Y., Coetzee, W. A., Vega-Saenz De Miera, E., et al. (1997). Modulation of Kv4 channels, key components of rat ventricular transient outward K ${ }^{+}$current, by PKC. Am J Physiol. 273, H1775-1786.

Nakaya, H., Furusawa, Y., Ogura, T., et al. (2000). Inhibitory effects of JTV-519, a novel cardioprotective drug, on potassium currents and experimental atrial fibrillation in guinea-pig hearts. Br J Pharmacol. 131, 1363-1372.

Nerbonne, J. M. (2000). Molecular basis of functional voltage-gated $\mathrm{K}^{+}$channel diversity in the mammalian myocardium. J Physiol. 525, 285-298.

Nerbonne, J. M., Kass, R. S. (2005). Molecular physiology of cardiac repolarization. Physiol Rev. 85, 1205-1253.

Nissen, J. D., Diness, J. G., Diness, T. G., et al. (2009). Pharmacologically induced long QT type 2 can be rescued by activation of IKs with benzodiazepine R-L3 in isolated guinea pig cardiomyocytes. $J$ Cardiovasc Pharmacol. 54, 169-177.

Noma, A. (1983). ATP-regulated $\mathrm{K}^{+}$channels in cardiac muscle. Nature. 305, 147-148.

Nunez, L., Vaquero, M., Gomez, R., et al. (2006). Nitric oxide blocks hKv1.5 channels by S-nitrosylation and by a cyclic GMP-dependent mechanism. Cardiovasc Res. 72, 80-89.

O'Connell, A. D., Morton, M. J., \& Hunter, M. (2002). Two-pore domain $\mathrm{K}^{+}$channels-molecular sensors. Biochim Biophys Acta. 1566, 152-161.

O'Rourke, B. (2004). Evidence for mitochondrial $\mathrm{K}^{+}$channels and their role in cardioprotection. Circ Res. 94, 420-432.

Oldenburg, O., Yang, X. M., Krieg, T., et al. (2003). P1075 opens mitochondrial K(ATP) channels and generates reactive oxygen species resulting in cardioprotection of rabbit hearts. J Mol Cell Cardiol. 35, 1035-1042.

Olson, T. M., Alekseev, A. E., Liu, X. K., et al. (2006). Kv1.5 channelopathy due to KCNA5 loss-of-function mutation causes human atrial fibrillation. Hum Mol Genet. 15, 2185-2191.

Park, S., Lim, B. B., Perez-Terzic, C., et al. (2008). Interaction of asymmetric ABCC9-encoded nucleotide binding domains determines $\mathrm{K}_{\mathrm{ATP}}$ channel SUR2A catalytic activity. J Proteome Res. 7, 1721-1728.

Perrin, M. J., Subbiah, R. N., Vandenberg, J. I., et al. (2008). Human ether-a-go-go related gene (hERG) K channels: function and dysfunction. Prog Biophys Mol Biol. 98, 137-148. 
Perry, M., Sachse, F. B., Abbruzzese, J., et al. (2009). PD-118057 contacts the pore helix of hERG1 channels to attenuate inactivation and enhance $\mathrm{K}^{+}$conductance. Proc Natl Acad Sci U S A. 106, 20075-20080.

Perry, M., Sachse, F. B., \& Sanguinetti, M. C. (2007). Structural basis of action for a human ether-a-go-go-related gene 1 potassium channel activator. Proc Natl Acad Sci U S A. 104, 13827-13832.

Po, S., Snyders, D. J., Baker, R., et al. (1992). Functional expression of an inactivating potassium channel cloned from human heart. Circ Res. 71, 732-736.

Po, S. S., Wu, R. C., Juang, G. J., et al. (2001). Mechanism of alpha-adrenergic regulation of expressed hKv4.3 currents. Am J Physiol Heart Circ Physiol. 281, H2518-2527.

Priori, S. G., Pandit, S. V., Rivolta, I., et al. (2005). A novel form of short QT syndrome (SQT3) is caused by a mutation in the KCNJ2 gene. Circ Res. 96, 800-807.

Radicke, S., Cotella, D., Graf, E. M., et al. (2005). Expression and function of dipeptidyl-aminopeptidase-like protein 6 as a putative beta-subunit of human cardiac transient outward current encoded by Kv4.3. J Physiol. 565, 751-756.

Raschi, E., Ceccarini, L., De Ponti, F., et al. (2009). hERG-related drug toxicity and models for predicting hERG liability and QT prolongation. Expert Opin Drug Metab Toxicol. 5, 1005-1021.

Rees, S. A., Curtis, M. J. (1993). Specific IK1 blockade: a new antiarrhythmic mechanism? Effect of RP58866 on ventricular arrhythmias in rat, rabbit, and primate. Circulation. 87, 1979-1989.

Regan, C. P., Kiss, L., Stump, G. L., et al. (2008). Atrial antifibrillatory effects of structurally distinct $I_{\text {Kur }}$ blockers 3-[(dimethylamino)methyl]-6-methoxy-2-methyl-4-phenylisoquinolin-1(2H)-one and 2-phenyl-1,1-dipyridin-3-yl-2-pyrrolidin-1-yl-ethanol in dogs with underlying heart failure. $J$ Pharmacol Exp Ther. 324, 322-330.

Regan, C. P., Stump, G. L., Wallace, A. A., et al. (2007). In vivo cardiac electrophysiologic and antiarrhythmic effects of an isoquinoline $\mathrm{I}_{\mathrm{Kur}}$ blocker, ISQ-1, in rat, dog, and nonhuman primate. $J$ Cardiovasc Pharmacol. 49, 236-245.

Regan, C. P., Wallace, A. A., Cresswell, H. K., et al. (2006). In vivo cardiac electrophysiologic effects of a novel diphenylphosphine oxide $I_{K u r}$ blocker, (2-Isopropyl-5-methylcyclohexyl) diphenylphosphine oxide, in rat and nonhuman primate. J Pharmacol Exp Ther. 316, 727-732.

Reyes, S., Park, S., Johnson, B. D., et al. (2009). K(ATP) channel Kir6.2 E23K variant overrepresented in human heart failure is associated with impaired exercise stress response. Hum Genet. [Epub ahead of print]

Robitaille, M., Ramakrishnan, N., Baragli, A., et al. (2009). Intracellular trafficking and assembly of specific Kir3 channel/G protein complexes. Cell Signal. 21, 488-501.

Roden, D. M., Woosley, R. L., \& Primm, R. K. (1986). Incidence and clinical features of the quinidine-associated long QT syndrome: implications for patient care. Am Heart J. 111, 1088-1093.

Rottlaender, D., Boengler, K., Wolny, M., et al. (2010). Connexin 43 acts as a cytoprotective mediator of signal transduction by stimulating mitochondrial KATP channels in mouse cardiomyocytes. J Clin Invest. 120, 1441-1453

Roy, D., Rowe, B. H., Stiell, I. G., et al. (2004). A randomized, controlled trial of RSD1235, a novel anti-arrhythmic agent, in the treatment of recent onset atrial fibrillation. J Am Coll Cardiol. 44, 2355-2361.

Salata, J. J., Jurkiewicz, N. K., Wang, J., et al. (1998). A novel benzodiazepine that activates cardiac slow delayed rectifier K+ currents. Mol Pharmacol. 54, 220-230.

Sanguinetti, M. C., Curran, M. E., Zou, A., et al. (1996). Coassembly of K(V)LQT1 and minK (IsK) proteins to form cardiac I(Ks) potassium channel. Nature. 384, 80-83.

Sanguinetti, M. C., Jiang, C., Curran, M. E., et al. (1995). A mechanistic link between an inherited and an acquired cardiac arrhythmia: HERG encodes the $\mathrm{I}_{\mathrm{Kr}}$ potassium channel. Cell. 81, 299-307.

Sanguinetti, M. C., Jurkiewicz, N. K. (1990). Two components of cardiac delayed rectifier K+ current. Differential sensitivity to block by class III antiarrhythmic agents. J Gen Physiol. 96, 195-215.

Sanguinetti, M. C., Jurkiewicz, N. K., Scott, A., et al. (1991). Isoproterenol antagonizes prolongation of refractory period by the class III antiarrhythmic agent E-4031 in guinea pig myocytes. Mechanism of action. Circ Res. 68, 77-84.

Schram, G., Pourrier, M., Melnyk, P., et al. (2002). Differential distribution of cardiac ion channel expression as a basis for regional specialization in electrical function. Circ Res. 90, 939-950.

Seebohm, G., Chen, J., Strutz, N., et al. (2003). Molecular determinants of KCNQ1 channel block by a benzodiazepine. Mol Pharmacol. 64, 70-77.

Seino, S., Miki, T. (2003). Physiological and pathophysiological roles of ATP-sensitive $\mathrm{K}^{+}$channels. Prog Biophys Mol Biol. 81, 133-176.

Seki, A., Hagiwara, N., \& Kasanuki, H. (1999). Effects of propafenone on $\mathrm{K}^{+}$currents in human atrial myocytes. Br J Pharmacol. 126, 1153-1162. 
Sergeant, G. P., Ohya, S., Reihill, J. A., et al. (2005). Regulation of Kv4.3 currents by $\mathrm{Ca}^{2+} /$ calmodulin-dependent protein kinase II. Am J Physiol Cell Physiol. 288, C304-313.

Shimizu, W., Antzelevitch, C. (1998). Cellular basis for the ECG features of the LQT1 form of the long-QT syndrome: effects of beta-adrenergic agonists and antagonists and sodium channel blockers on transmural dispersion of repolarization and torsade de pointes. Circulation. 98, 2314-2322.

Simard, C., Drolet, B., Yang, P., et al. (2005). Polymorphism screening in the cardiac $\mathrm{K}^{+}$channel gene KCNA5. Clin Pharmacol Ther. 77, 138-144.

Snyders, D. J. (1999). Structure and function of cardiac potassium channels. Cardiovasc Res. 42, 377-390.

Snyders, D. J., Tamkun, M. M., \& Bennett, P. B. (1993). A rapidly activating and slowly inactivating potassium channel cloned from human heart. Functional analysis after stable mammalian cell culture expression. J Gen Physiol. 101, 513-543.

Snyders, D. J., Yeola, S. W. (1995). Determinants of antiarrhythmic drug action. Electrostatic and hydrophobic components of block of the human cardiac hKv1.5 channel. Circ Res. 77, 575-583.

Splawski, I., Tristani-Firouzi, M., Lehmann, M. H., et al. (1997). Mutations in the hminK gene cause long QT syndrome and suppress IKs function. Nat Genet. 17, 338-340.

Stephan, D., Winkler, M., Kuhner, P., et al. (2006). Selectivity of repaglinide and glibenclamide for the pancreatic over the cardiovascular K(ATP) channels. Diabetologia. 49, 2039-2048.

Stump, G. L., Smith, G. R., Tebben, A. J., et al. (2003). In vivo canine cardiac electrophysiologic profile of 1,4-benzodiazepine IKs blockers. J Cardiovasc Pharmacol. 42, 105-112.

Stump, G. L., Wallace, A. A., Regan, C. P., et al. (2005). In vivo antiarrhythmic and cardiac electrophysiologic effects of a novel diphenylphosphine oxide $\mathrm{I}_{\mathrm{Kur}}$ blocker (2-isopropyl-5-methylcyclohexyl) diphenylphosphine oxide. J Pharmacol Exp Ther. 315, 1362-1367.

$\mathrm{Su}, \mathrm{Z}$., Chen, J., Martin, R. L., et al. (2006). Block of hERG channel by ziprasidone: biophysical properties and molecular determinants. Biochem Pharmacol. 71, 278-286.

$\mathrm{Su}, \mathrm{Z}$., Limberis, J., Souers, A., et al. (2009). Electrophysiologic characterization of a novel hERG channel activator. Biochem Pharmacol. 77, 1383-1390.

Sun, D. D., Wang, H. C., Wang, X. B., et al. (2008). Tanshinone IIA: a new activator of human cardiac KCNQ1/KCNE1 (I(Ks)) potassium channels. Eur J Pharmacol. 590, 317-321.

Taglialatela, M., Pannaccione, A., Iossa, S., et al. (1999). Modulation of the K(+) channels encoded by the human ether-a-gogo-related gene-1 (hERG1) by nitric oxide. Mol Pharmacol. 56, 1298-1308.

Takemasa, H., Nagatomo, T., Abe, H., et al. (2008). Coexistence of hERG current block and disruption of protein trafficking in ketoconazole-induced long QT syndrome. Br J Pharmacol. 153, 439-447.

Takimoto, K., Fomina, A. F., Gealy, R., et al. (1993). Dexamethasone rapidly induces Kv1.5 K ${ }^{+}$channel gene transcription and expression in clonal pituitary cells. Neuron. 11, 359-369.

Tamargo, J., Caballero, R., Gomez, R., et al. (2009). I(Kur)/Kv1.5 channel blockers for the treatment of atrial fibrillation. Expert Opin Investig Drugs. 18, 399-416.

Tamargo, J., Caballero, R., Gomez, R., et al. (2004). Pharmacology of cardiac potassium channels. Cardiovasc Res. 62, 9-33.

Tang, Q., Li, Z. Q., Li, W., et al. (2008). The 5-HT2 antagonist ketanserin is an open channel blocker of human cardiac ether-a-go-go-related gene (hERG) potassium channels. Br J Pharmacol. 155, 365-373.

Terrenoire, C., Clancy, C. E., Cormier, J. W., et al. (2005). Autonomic control of cardiac action potentials: role of potassium channel kinetics in response to sympathetic stimulation. Circ Res. 96, e25-34.

Thomas, D., Gut, B., Karsai, S., et al. (2003). Inhibition of cloned HERG potassium channels by the antiestrogen tamoxifen. Naunyn Schmiedebergs Arch Pharmacol. 368, 41-48.

Thomas, D., Karle, C. A., \& Kiehn, J. (2006). The cardiac hERG/IKr potassium channel as pharmacological target: structure, function, regulation, and clinical applications. Curr Pharm Des. 12, 2271-2283.

Thomas, G. P., Gerlach, U., \& Antzelevitch, C. (2003). HMR 1556, a potent and selective blocker of slowly activating delayed rectifier potassium current. J Cardiovasc Pharmacol. 41, 140-147.

Tian, M., Dong, M. Q., Chiu, S. W., et al. (2006). Effects of the antifungal antibiotic clotrimazole on human cardiac repolarization potassium currents. Br J Pharmacol. 147, 289-297.

Tipparaju, S. M., Liu, S. Q., Barski, O. A., et al. (2007). NADPH binding to beta-subunit regulates inactivation of voltage-gated $\mathrm{K}(+)$ channels. Biochem Biophys Res Commun. 359, 269-276.

Tong, Y., Brandt, G. S., Li, M., et al. (2001). Tyrosine decaging leads to substantial membrane trafficking during modulation of an inward rectifier potassium channel. J Gen Physiol. 117, 103-118.

Tristani-Firouzi, M., Sanguinetti, M. C. (2003). Structural determinants and biophysical properties of HERG and KCNQ1 channel gating. J Mol Cell Cardiol. 35, 27-35.

Tsuboi, T., Lippiat, J. D., Ashcroft, F. M., et al. (2004). ATP-dependent interaction of the cytosolic domains of the inwardly rectifying $\mathrm{K}^{+}$channel Kir6.2 revealed by fluorescence resonance energy transfer. Proc Natl Acad Sci U S A. 101, 76-81. 
Turgeon, J., Daleau, P., Bennett, P. B., et al. (1994). Block of $\mathrm{I}_{\mathrm{Ks}}$, the slow component of the delayed rectifier $\mathrm{K}+$ current, by the diuretic agent indapamide in guinea pig myocytes. Circ Res. 75, 879-886.

Unsold, B., Kerst, G., Brousos, H., et al. (2000). KCNE1 reverses the response of the human $\mathrm{K}^{+}$channel KCNQ1 to cytosolic $\mathrm{pH}$ changes and alters its pharmacology and sensitivity to temperature. Pflugers Arch. 441, 368-378.

Voigt, N., Friedrich, A., Bock, M., et al. (2007). Differential phosphorylation-dependent regulation of constitutively active and muscarinic receptor-activated $\mathrm{I}_{\mathrm{K}, \mathrm{ACh}}$ channels in patients with chronic atrial fibrillation. Cardiovasc Res. 74, 426-437.

Walsh, K. B., Kass, R. S. (1991). Distinct voltage-dependent regulation of a heart-delayed $\mathrm{I}_{\mathrm{K}}$ by protein kinases A and C. Am J Physiol. 261, C1081-1090.

Wang, D., Armstrong, D. L. (2000). Tetraethylammonium potentiates the activity of muscarinic potassium channels in guinea-pig atrial myocytes. J Physiol. 529, 699-705.

Wang, J. W., Yazawa, K., Hao, L. Y., et al. (2007). Verrucotoxin inhibits $\mathrm{K}_{\mathrm{ATP}}$ channels in cardiac myocytes through a muscarinic $\mathrm{M}_{3}$ receptor-PKC pathway. Eur J Pharmacol. 563, 172-179.

Wang, X., Wu, B. W., \& Wu, D. M. (2006). Action of AMP579 and adenosine on potassium or sodium ionic channels in isolated rat and guinea pig ventricular myocytes. Үао Хие Хие Вао. 41, 716-720.

Wang, Z., Fermini, B., \& Nattel, S. (1993). Sustained depolarization-induced outward current in human atrial myocytes. Evidence for a novel delayed rectifier $\mathrm{K}^{+}$current similar to Kv1.5 cloned channel currents. Circ Res. 73, 1061-1076.

Wang, Z., Fermini, B., \& Nattel, S. (1995). Effects of flecainide, quinidine, and 4-aminopyridine on transient outward and ultrarapid delayed rectifier currents in human atrial myocytes. J Pharmacol Exp Ther. 272, 184-196.

Wettwer, E., Hala, O., Christ, T., et al. (2004). Role of $I_{K u r}$ in controlling action potential shape and contractility in the human atrium: influence of chronic atrial fibrillation. Circulation. 110, 2299-2306.

Wible, B. A., De Biasi, M., Majumder, K., et al. (1995). Cloning and functional expression of an inwardly rectifying K+ channel from human atrium. Circ Res. 76, 343-350.

Wirth, K. J., Brendel, J., Steinmeyer, K., et al. (2007). In vitro and in vivo effects of the atrial selective ntiarrhythmic compound AVE1231. J Cardiovasc Pharmacol. 49, 197-206.

Witchel, H. J., Dempsey, C. E., Sessions, R. B., et al. (2004). The low-potency, voltage-dependent HERG blocker propafenone--molecular determinants and drug trapping. Mol Pharmacol. 66, 1201-1212.

Wojtovich, A. P., Brookes, P. S. (2009). The complex II inhibitor atpenin A5 protects against cardiac ischemia-reperfusion injury via activation of mitochondrial $\mathrm{K}_{\mathrm{ATP}}$ channels. Basic Res Cardiol. 104, 121-129.

Wu, J., Ding, W. G., Matsuura, H., et al. (2009). Inhibitory actions of the phosphatidylinositol 3-kinase inhibitor LY294002 on the human Kv1.5 channel. Br J Pharmacol. 156, 377-387.

Xia, M., Jin, Q., Bendahhou, S., et al. (2005). A Kir2.1 gain-of-function mutation underlies familial atrial fibrillation. Biochem Biophys Res Commun. 332, 1012-1019.

Xiao, G. S., Zhou, J. J., Cheung, Y. F., et al. (2003). Effects of U50,488H on transient outward and ultra-rapid delayed rectifier $\mathrm{K}^{+}$currents in young human atrial myocytes. Eur J Pharmacol. 473, 97-103.

Xie, L. H., John, S. A., Ribalet, B., et al. (2007). Activation of inwardly rectifying potassium (Kir) channels by phosphatidylinosital-4,5-bisphosphate (PIP2): interaction with other regulatory ligands. Prog Biophys Mol Biol. 94, 320-335.

Xie, L. H., John, S. A., Ribalet, B., et al. (2008). Phosphatidylinositol-4,5-bisphosphate (PIP2) regulation of strong inward rectifier Kir2.1 channels: multilevel positive cooperativity. J Physiol. 586, 1833-1848.

$\mathrm{Xu}, \mathrm{X}$., Kanda, V. A., Choi, E., et al. (2009). MinK-dependent internalization of the $\mathrm{I}_{\mathrm{Ks}}$ potassium channel. Cardiovasc Res. 82, 430-438.

Yang, B., Lin, H., Xiao, J., et al. (2007). The muscle-specific microRNA miR-1 regulates cardiac arrhythmogenic potential by targeting GJA1 and KCNJ2. Nat Med. 13, 486-491.

Yang, B. F., Li, G. R., Xu, C. Q., et al. (1999). Effects of RP58866 on transmembrane $\mathrm{K}^{+}$currents in mammalian ventricular myocytes. Zhongguo Yao Li Xue Bao. 20, 961-969.

Yang, I. C., Scherz, M. W., Bahinski, A., et al. (2000). Stereoselective interactions of the enantiomers of chromanol 293B with human voltage-gated potassium channels. J Pharmacol Exp Ther. 294, 955-962.

Ye, B., Kroboth, S. L., Pu, J. L., et al. (2009). Molecular identification and functional characterization of a mitochondrial sulfonylurea receptor 2 splice variant generated by intraexonic splicing. Circ Res. 105, 1083-1093.

Yeh, Y. H., Ehrlich, J. R., Qi, X., et al. (2007). Adrenergic control of a constitutively active acetylcholine-regulated potassium current in canine atrial cardiomyocytes. Cardiovasc Res. 74, 406-415.

Yue, L., Feng, J., Li, G. R., et al. (1996). Characterization of an ultrarapid delayed rectifier potassium 
channel involved in canine atrial repolarization. J Physiol. 496, 647-662.

Yue, L., Feng, J., Wang, Z., et al. (1999). Adrenergic control of the ultrarapid delayed rectifier current in canine atrial myocytes. J Physiol. 516, 385-398.

Yue, L., Melnyk, P., Gaspo, R., et al. (1999). Molecular mechanisms underlying ionic remodeling in a dog model of atrial fibrillation. Circ Res. 84, 776-784.

Yuill, K. H., Borg, J. J., Ridley, J. M., et al. (2004). Potent inhibition of human cardiac potassium (HERG) channels by the anti-estrogen agent clomiphene-without QT interval prolongation. Biochem Biophys Res Commun. 318, 556-561.

Yumoto, Y., Horie, M., Kubota, T., et al. (2004). Bepridil block of recombinant human cardiac $\mathrm{I}_{\mathrm{Ks}}$ current shows a time-dependent unblock. J Cardiovasc Pharmacol. 43, 178-182.

Zareba, W., Cygankiewicz, I. (2008). Long QT syndrome and short QT syndrome. Prog Cardiovasc Dis. 51, 264-278.

Zhang, D. Y., Lau, C. P., \& Li, G. R. (2009). Human Kir2.1 channel carries a transient outward potassium current with inward rectification. Pflugers Arch. 457, 1275-1285.

Zhang, D. Y., Wang, Y., Lau, C. P., et al. (2008). Both EGFR kinase and Src-related tyrosine kinases regulate human ether-a-go-go-related gene potassium channels. Cell Signal. 20, 1815-1821.

Zhang, L., Benson, D. W., Tristani-Firouzi, M., et al. (2005). Electrocardiographic features in Andersen-Tawil syndrome patients with KCNJ2 mutations: characteristic T-U-wave patterns predict the KCNJ2 genotype. Circulation. 111, 2720-2726.

Zhang, S., Zhou, Z., Gong, Q., et al. (1999). Mechanism of block and identification of the verapamil binding domain to HERG potassium channels. Circ Res. 84, 989-998.

Zhang, Y., Liu, Y., Wang, T., et al. (2006). Resveratrol, a natural ingredient of grape skin: antiarrhythmic efficacy and ionic mechanisms. Biochem Biophys Res Commun. 340, 1192-1199.

Zhou, J., Augelli-Szafran, C. E., Bradley, J. A., et al. (2005). Novel potent human ether-a-go-go-related gene (hERG) potassium channel enhancers and their in vitro antiarrhythmic activity. Mol Pharmacol. 68, 876-884.

Zicha, S., Xiao, L., Stafford, S., et al. (2004). Transmural expression of transient outward potassium current subunits in normal and failing canine and human hearts. $J$ Physiol. 561, 735-748.

Zingman, L. V., Alekseev, A. E., Hodgson-Zingman, D. M., et al. (2007). ATP-sensitive potassium channels: metabolic sensing and cardioprotection. J Appl Physiol. 103, 1888-1893.

Zingman, L. V., Hodgson, D. M., Bast, P. H., et al. (2002). Kir6.2 is required for adaptation to stress. Proc Natl Acad Sci U S A. 99, 13278-13283.

Zunkler, B. J. (2006). Human ether-a-go-go-related (HERG) gene and ATP-sensitive potassium channels as targets for adverse drug effects. Pharmacol Ther. 112, 12-37. 
Table 1. Pharmacological blockers and activators of cardiac potassium channels

\begin{tabular}{|c|c|c|c|c|c|c|c|c|c|}
\hline$\overline{\text { Drug }}$ & $\mathrm{I}_{\mathrm{to1} 1} / \mathrm{Kv} 4.3$ & $\mathrm{I}_{\mathrm{Kur}} / \mathrm{Kv} 1.5$ & $\mathrm{I}_{\mathrm{Kr}} / \mathrm{hERG}$ & $\mathrm{I}_{\mathrm{Ks}}$ & $\mathrm{I}_{\mathrm{KACh}}$ & $\mathrm{I}_{\text {KATP }}$ & $\mathrm{I}_{\mathrm{K} 1}$ & Species & References \\
\hline \multicolumn{10}{|l|}{ Blocker } \\
\hline Acacetin & $9.3 \mu \mathrm{M}$ & $3.2 \mu \mathrm{M}$ & & & $4 \mu \mathrm{M}$ & & & Human/GP atrial myocytes & (Li et al., 2008) \\
\hline Adenosine & & & & & & & $20.7 \mu \mathrm{M}$ & Rat/GP cardiac myocytes & (Wang et al., 2006) \\
\hline AMP579 & & & & & & & $4.1 \mu \mathrm{M}$ & Rat/GP atrial myocytes & (Wang et al., 2006) \\
\hline AVE0118 & $3.4 \mu \mathrm{M}$ & $6.2 \mu \mathrm{M}$ & $10 \mu \mathrm{M}$ & & & & & $\mathrm{CHO}$ & (Gogelein et al., 2004) \\
\hline AVE1231 & $5.9 \mu \mathrm{M}$ & $3.6 \mu \mathrm{M}$ & & & $8.4 \mu \mathrm{M}$ & & & Pig atrial myocytes/CHO & (Wirth et al., 2007) \\
\hline $\mathrm{BaCl}_{2}$ & & & & & & & $19.6 \mu \mathrm{M}$ & hIRK/Oocytes & (Wible et al., 1995) \\
\hline \multicolumn{10}{|c|}{ Cinnamyl-3,4-dihydroxy-alp } \\
\hline ha-cyanocinnamate & & $5.7 \mu \mathrm{M}$ & & & & & & $\mathrm{CHO}$ & (Gong et al., 2008) \\
\hline Citalopram & & $2.8 \mu \mathrm{M}$ & & & & & & $\mathrm{CHO}$ & (Lee et al., 2010) \\
\hline Clomiphene & & & $180 \mathrm{nM}$ & & & & & HEK293 cells & (Yuill et al., 2004) \\
\hline Clotrimazole & $29.5 \mu \mathrm{M}$ & $7.6 \mu \mathrm{M}$ & $3.6 \mu \mathrm{M}$ & $15.1 \mu \mathrm{M}$ & & & & Human atrial myocytes/HEK293 & (Tian et al., 2006) \\
\hline Diltiazen & $29.2 \mu \mathrm{M}$ & $11.2 \mu \mathrm{M}$ & & & & & & Human atrial myocytes & (Gao et al., 2005) \\
\hline DPO-1 & & $20 \mathrm{nM}$ & & & & & & Human atrial myocytes/CHO & (Lagrutta et al., 2006) \\
\hline Docosahexaenoic acid & $4.1 \mu \mathrm{M}$ & $4.3 \mu \mathrm{M}$ & & & & & & Human atrial myocytes & (Li et al., 2009) \\
\hline Eicosapentaenoic acid & $6.2 \mu \mathrm{M}$ & $17.5 \mu \mathrm{M}$ & & & & & & Human atrial myocytes & (Li et al., 2009) \\
\hline JTV-519(K201) & & & & & $<2.4 \mu \mathrm{M}$ & & & GP atrial myocytes & (Nakaya et al., 2000) \\
\hline KB130015 & & & & & $0.6 \mu \mathrm{M}$ & & & GP atrial myocytes & (Brandts et al., 2004) \\
\hline Ketanserin & & & $110 \mathrm{nM}$ & & & & & HEK293 & (Tang et al., 2008) \\
\hline Ketoconazole & & & $1.9 \mu \mathrm{M}$ & & & & & HEK293 & (Takemasa et al., 2008) \\
\hline
\end{tabular}


Table 1 (continued)

\begin{tabular}{|c|c|c|c|c|c|c|c|c|}
\hline Drug & $\mathrm{I}_{\mathrm{to} 1} / \mathrm{Kv} 4.3$ & $\mathrm{I}_{\mathrm{Kur}} / \mathrm{Kv} 1.5$ & $\mathrm{I}_{\mathrm{Kr}} / \mathrm{hERG}$ & $\mathrm{I}_{\mathrm{Ks}}$ & $\mathrm{I}_{\mathrm{KACh}}$ & $\mathrm{I}_{\text {KATP }}$ & Species & References \\
\hline LY294002 & & $7.9 \mu \mathrm{M}$ & & & & & CHO cells & (Wu et al., 2009) \\
\hline Nifendipine & $26.8 \mu \mathrm{M}$ & $8.2 \mu \mathrm{M}$ & & & & & Human atrial myocytes & (Gao et al., 2005) \\
\hline NIP-151 & & & & & $1.6 \mathrm{nM}$ & & HEK293 cells & (Hashimoto et al., 2008) \\
\hline Nordihydroguaiaretic acid & & $16.4 \mu \mathrm{M}$ & & & & & CHO cells & (Gong et al., 2008) \\
\hline Quinidine & & & $0.6 \mu \mathrm{M}$ & & & & $\mathrm{CHO}$ cells & (McPate et al., 2006) \\
\hline Raloxifene & $0.9 \mu \mathrm{M}$ & $0.7 \mu \mathrm{M}$ & & & & & Human atrial myocytes & (Liu et al., 2007) \\
\hline S0100176 & & $0.7 \mu \mathrm{M}$ & & & & & Oocytes & (Decher et al., 2004) \\
\hline SD-3212 & & & & & $<0.4 \mu \mathrm{M}$ & & GP atrial myovytes & (Hara and Nakaya, 1995) \\
\hline Spironolactone & $27 \% / 1 \mu \mathrm{M}$ & $23 \% / 1 \mu \mathrm{M}$ & & $38 \% / 1 \mu \mathrm{M}$ & & & & (Gomez 2005 \\
\hline Canrenoic acid & $27 \% / 1 \mathrm{nM}$ & $19 \% / 1 \mathrm{nM}$ & $104 \mathrm{nM}$ & $223 \mathrm{nM}$ & & & $\mathrm{CHO} / L t k^{-}$ & Caballero, 2003) \\
\hline Tertiapin/Tertiapin Q & & & & & $10 \mathrm{nM}$ & & Oocytes & (Jin and Lu, 1998) \\
\hline U50488H & $12.4 \mu \mathrm{M}$ & $3.3 \mu \mathrm{M}$ & & & & & Human atrial myocytes & (Xiao et al., 2003) \\
\hline U73122/U73343 & & & & & $0.5 \mu \mathrm{M}$ & & HEK293 cells & (Klose et al., 2008) \\
\hline Verapamil & & $3.2 \mu \mathrm{M}$ & & & & & Human atrial myocytes & (Gao et al., 2004) \\
\hline Vernakalant & $30 \mu \mathrm{M}$ & $13 \mu \mathrm{M}$ & $21 \mu \mathrm{M}$ & & & & HEK293 cells & (Fedida et al., 2005) \\
\hline Verrucotoxin & & & & & & $16 \mu \mathrm{g} / \mathrm{ml}$ & GP atrial myocytes & (Wang et al., 2007) \\
\hline Ziprasidone & & & $120 \mathrm{nM}$ & & & & HEK293 cells & (Su et al., 2006) \\
\hline \multicolumn{9}{|l|}{ Activator } \\
\hline A-312110 & & & & & & $4.3 \mathrm{nM}$ & GP cells & (Davis-Taber et al., 2003) \\
\hline A-935142 & & & $60 \mu \mathrm{M}$ & & & & HEK293 cells & (Su et al., 2009) \\
\hline Adenosine & $2.3 \mu \mathrm{M}$ & & & & & & Rat cardiac myocytes & (Wang et al., 2006) \\
\hline
\end{tabular}


Table 1 (continued)

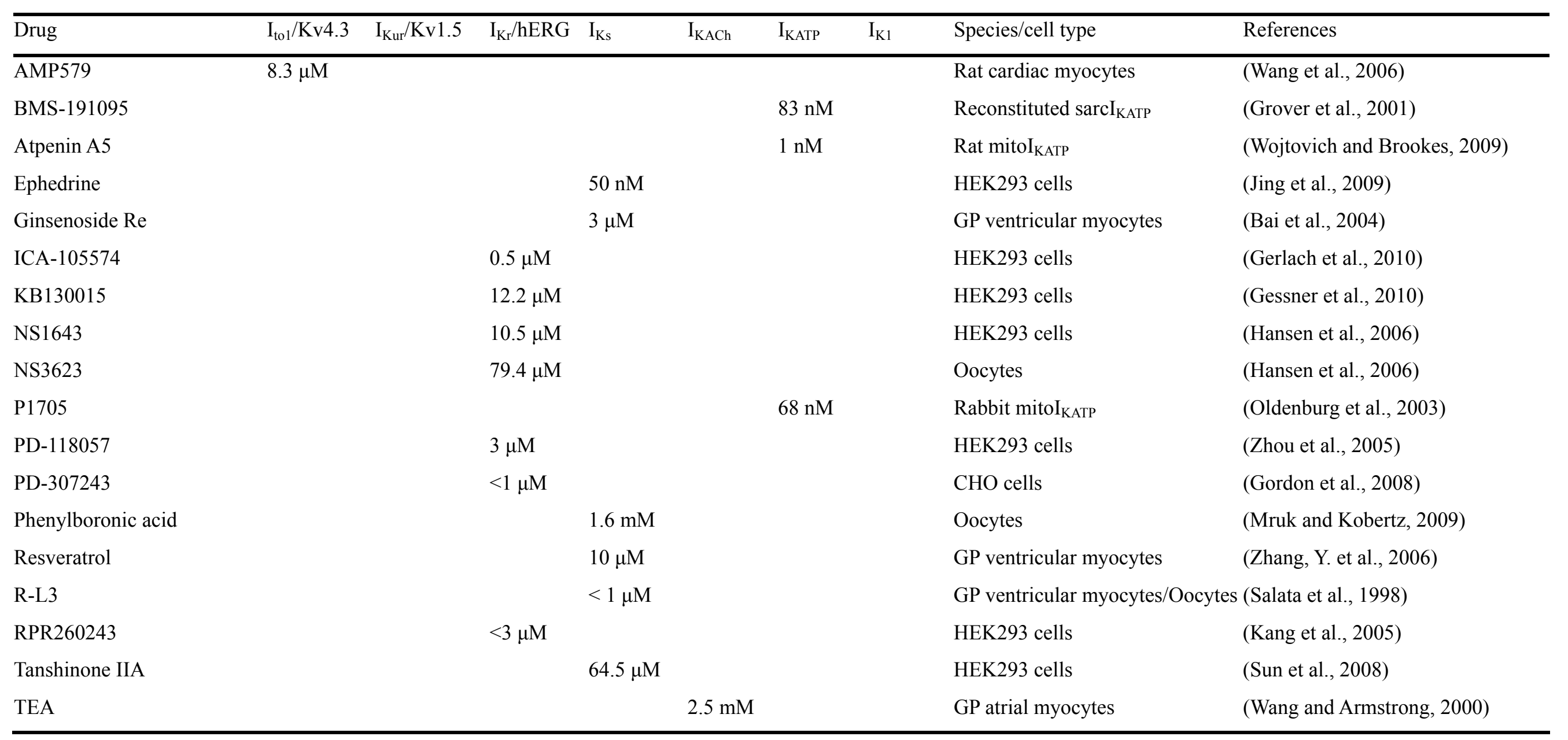

Data are expressed as $\mathrm{IC}_{50}$ (for blockers) or $\mathrm{EC}_{50}$ (for activators) values (concentrations producing $50 \%$ inhibition or enhancement of the current or half-maximal effects), and some values are estimated according to the reference, which are mainly from the reports after 2003. Please refer to the review (Tamargo et al., 2004) for the information before 2003. GP, guinea pig; CHO, Chinese hamster ovary. 


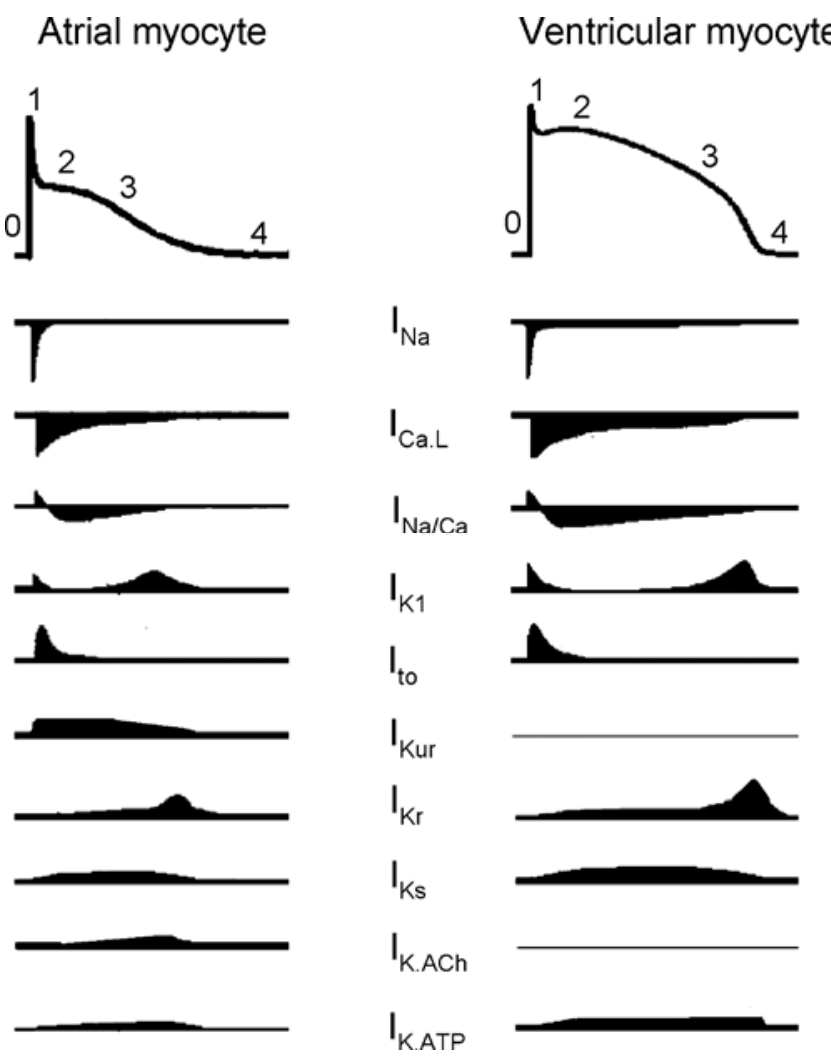

Figure 1. Ionic current contribution to human atrial and ventricular action potentials. The graph schematically shows that the major ionic currents contribute to the action potential waveforms at different phases. The action potentials are recorded from a human atrial myocyte and ventricular myocyte. The depolarizing inward (downward) currents and repolarizing outward (upward) currents represent the potential contribution to the action potentials. 
A: Six transmembrane one-pore
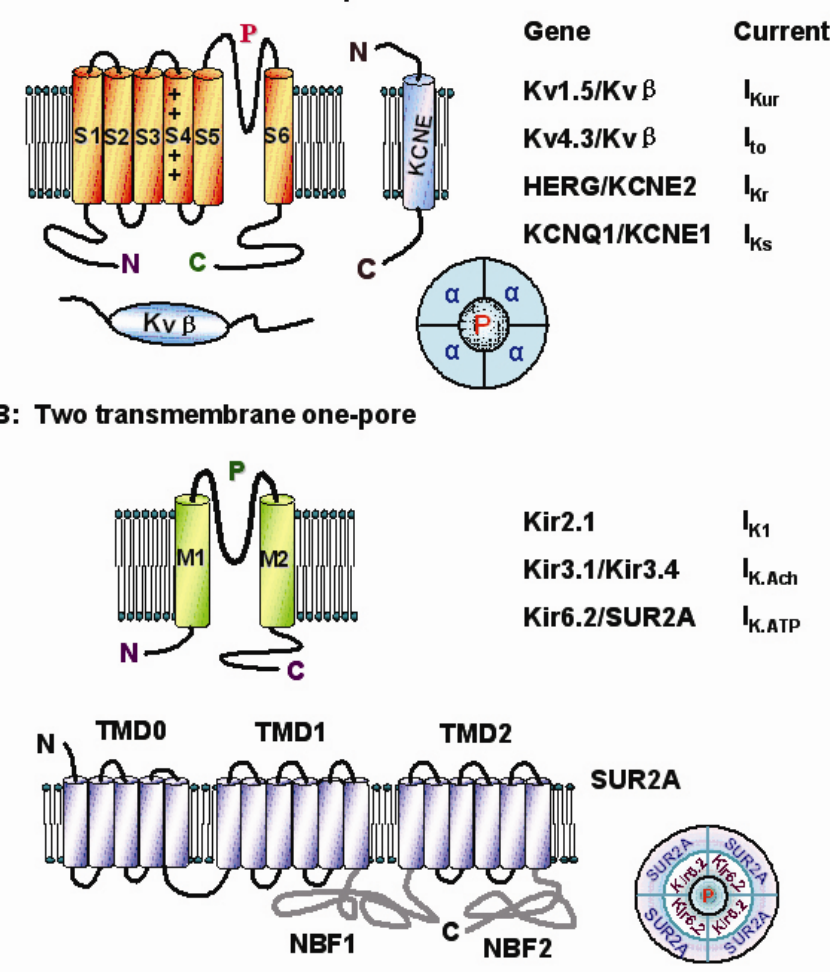

C: Four transmembrane two-pore

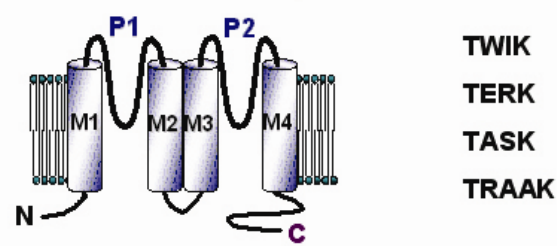

Figure 2. Schematic topology of the potassium channels subunits. A. 6-TM subunits, the Kv channels are composed of four subunits each containing six-transmembrane segments (S1-S6) and one conducting pore $(\mathrm{P})$ domain between S5 and S6 with a positively charged voltage sensor S4. The auxiliary $\beta$-subunit may be cytoplasmic protein $\left(\mathrm{Kv} \beta\right.$, for $\mathrm{I}_{\mathrm{Kur}}$ and $\left.\mathrm{I}_{\mathrm{tol}}\right)$ or single transmembrane protein (KCNE1, for $\mathrm{I}_{\mathrm{Kr}}$ and $\left.\mathrm{I}_{\mathrm{Ks}}\right)$. The inset shows the general assembly of $\mathrm{K}^{+}$channels. The channel tetramer may be homogenous (with four identical $\alpha$-subunits) or heterogenous (with four different $\alpha$-subunits). B. 2-TM subunits, the $\alpha$-subunits of the inward rectifier $\mathrm{K}^{+}$channels (Kir2.x, Kir 3.x, and Kir6.x) contain four subunits each containing two transmembrane segments (M1 and M2) with one pore. Cardiac I IATP channels are composed of four $\alpha$-subunits (Kir6.2), and four $\beta$-subunits sulfonylurea receptor (SUR2A) containing three transmembrane domains (TMD0-TMD2). C, 4-TM subunits. $\mathrm{K}_{2 \mathrm{P}}$ channels have four-transmembrane segments (M1-M4) with two pores. 